\title{
Conventional Selection of Mechanical Fasteners for Flat Belts
}

\author{
Karol Konecki ${ }^{1, *(\mathbb{D}}$, Dominik Wojtkowiak ${ }^{2}{ }^{\mathbb{D}}$, Krzysztof Talaśka ${ }^{2}$, Andrzej Kołodziej ${ }^{1}$ and Grzegorz Domek ${ }^{3}$ \\ 1 Calisia University, Nowy Świat 4, 62-800 Kalisz, Poland; a.kolodziej@akademia.kalisz.pl \\ 2 Institute of Machine Design, Poznan University of Technology, Piotrowo 3, 60-965 Poznań, Poland; \\ dominik.wojtkowiak@put.poznan.pl (D.W.); krzysztof.talaska@put.poznan.pl (K.T.) \\ 3 Faculty of Mechatronics, Kazimierz Wielki University, Chodkiewicza 30, 85-062 Bydgoszcz, Poland; \\ gdomek@ukw.edu.pl \\ * Correspondence: k.konecki@akademiakaliska.edu.pl
}

Citation: Konecki, K.; Wojtkowiak,

D.; Talaśka, K.; Kołodziej, A.; Domek,

G. Conventional Selection of

Mechanical Fasteners for Flat Belts.

Appl. Sci. 2021, 11, 2916. https://

doi.org/10.3390/app11072916

Academic Editor: Andrea Paglietti

Received: 23 February 2021

Accepted: 18 March 2021

Published: 24 March 2021

Publisher's Note: MDPI stays neutral with regard to jurisdictional claims in published maps and institutional affiliations.

Copyright: (C) 2021 by the authors. Licensee MDPI, Basel, Switzerland. This article is an open access article distributed under the terms and conditions of the Creative Commons Attribution (CC BY) license (https:// creativecommons.org/licenses/by/ $4.0 /)$.

\begin{abstract}
Due to the variety of materials used for flat belts of belt conveyors and the further development of material engineering in relation to these belts, the methods of their connection become an increasingly problematic issue. The belts can be connected mainly in three ways: vulcanized (weldable or heat-weldable), glued or mechanically. The latter method is one of the simplest and most universal in terms of the material variety of belts; however, there are many design variations of mechanical fasteners, and each of them has a certain advantage in a narrow group of properties, e.g., the thickness spectrum of a conveyor belt, the minimum diameter of a drive roller or the range of transferable longitudinal loads. The objective of this paper is to analyze the design solutions of commercial mechanical fasteners used mainly for flat rubber-fabric, composite or plastic belts. To fulfill this goal, a preliminary analysis of the stress distribution for an exemplary solid mechanical fastener was carried out in two cases: during ramp-up and during circulating around the roll, followed by a detailed review of commercial solutions available on the market. In addition to determining the current state of knowledge and technology and determining the state of ignorance, special algorithm and design maps have been created, thanks to which the process of selecting the right mechanical fastening will be easier. The overview includes several tables with detailed information on individual connection properties. Additionally, several design aspects were derived, within which individual mechanical connections may differ. This is to enable the generation of customized solutions in the future by proposing an appropriate mathematical model, on the basis of which it will be possible to generate optimal design properties for a given application.
\end{abstract}

Keywords: mechanical joining; mechanical fasteners; flat belts; belt conveyors

\section{Introduction}

The rapid increase in production, which characterizes the development of modern industry, requires systematic improvement on the level of organization and mechanization of production processes. This also applies to the state of organization and the development of in-plant systems and means of transport, which must ensure the continuous circulation of raw materials, semi-finished products and finished products by all production, control and storage stocks, as well as guarantee an uninterrupted production process of auxiliary materials [1].

There are two basic systems of internal transport solutions: intermittent transport and continuous transport. The first one is carried out by palletization and concretization, and it is moved with the help of mechanized equipment operated by an operator. The latter, in turn, concerns materials that are continuously moved without the operator's participation. Continuous transport includes, among others, conveyors.

Conveyors can be categorized, among other things, on the basis of the element transporting the transported material, the design, and operational features. In addition to beltless conveyors and conveyors with an intermediate medium, it is important to distinguish belt conveyors, which move the transported material using a belt, the main driving 
element of the conveyor. In addition to belt conveyors, there are also member conveyors, bucket conveyors, claw conveyors and pull-carrying conveyors. It should be mentioned here that, in general, belt conveyors are part of the group of devices using a belt drive, whose main feature is the transmission of torque over long distances. Belts are used because they are light and prevent the drive from emitting excessive noise [2]. Belt conveyors are also suitable for building modular systems of belt conveyors, which can be used in a transport automation system [3]. Belt conveyor transportation systems are also considered to be the most effective for handling large volumes of bulk material [4]. The disadvantages include the occurrence of transverse vibrations of the conveyor belts. These vibrations are caused by the eccentricity of the rollers, which results from production errors or from sticking of the transported material to the support rollers of the lower branch of the conveyor [5]. The properties of the conveyor belt itself are also very dependent on thermal and humidity conditions [6].

In the general design of belt conveyors, one can primarily distinguish a drive roller, a tension roller, a belt, carry idlers and return idlers [7]. The drive roller is coupled to the shaft of the motor or geared motor and transmits the torque to the belt system. The tension roller acts as a reversing roller, thanks to which the conveyor belt returns, and as a tensioning function, it is usually mounted on a movable guide that moves linearly thanks to the screw mechanism. In such a system, the conveyor belt forms a closed system, and therefore it is necessary to connect the conveyor belts. The above-mentioned structural elements are shown in Figure 1. There are also other types of structures, such as suspended belt conveyors, in which the conveyor belt is fastened in special brackets. These, in turn, are guided in tubular guides arranged on both sides of the belt along the length of the conveyor. It is, therefore, a hybrid of a traditional belt conveyor and a rail transport [8]. Belt conveyors, or rather tracks of their conveyor belts, can form both straight and curved tracks. There is also the option of curving the track of the conveyor belt through a special turning frame [9].

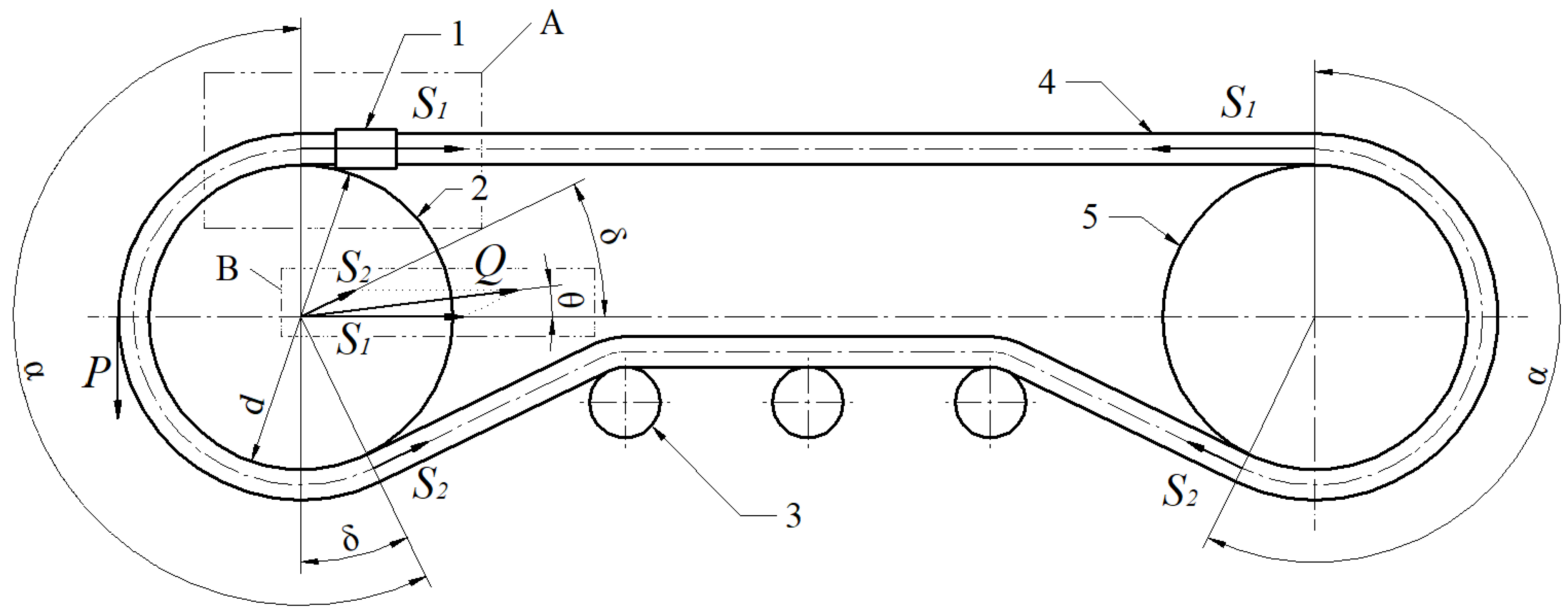

Figure 1. Structural diagram of a belt conveyor with the use of a mechanical connector. Structural description in the text of the article. Other markings: $\alpha$-angle of contact the roller by the conveyor belt, $\delta$-the lower belt deflection angle, which is the same as the angle between the force vectors in the upper and lower conveyor belt, $S_{1}$ - force in the upper band, $S_{2}$-force in the lower band, $P$-driving force, $d$-diameter of the roller, $\theta$-angle of deviation of the vector of the resultant force loading the shaft. (Detail A and Detail B are shown in the following drawings).

Among the conveyor belts, there are mainly elastic belts that transfer longitudinal and transverse forces resulting from loading with the transported material and own weight, as well as tensile forces arising during belt tensioning. Tensioning the belt is necessary to create on the surface of the driving roller the tractive force needed to overcome the resistance to movement of the conveyor and move the transported material to the desired level and distance. A rubber-fabric belt consists of several layers of rubber and fabric, i.e., spacers 
forming the core of the belt and transmitting mainly longitudinal and transverse tensile forces, running and bearing covers and side edges. Spacers can be made of cotton, cellulose fiber, viscose silk, polyamide (generally polyamide fibers are nylon, perlon, stylon, capron), polyester (generally polyester fibers are diolene, dacron, terylene), aromatic polyamide (Aramid, the name comes from ARomatische PolyAMID), or glass fiber-usually made of cross-weave fabrics. Covers, on the other hand, are most often made of rubber materials based on CR, NBR and PVC polymers in flame-retardant tapes, or SBR or NR/BR in flame retardant tapes. In addition to elastic fabric-rubber belts, you can also find belts made of the so-called TPU, i.e., thermoplastic polyurethane, most often reinforced with aramid. Thermoplastic polyurethane is a thermoplastic elastomer, which is characterized above all by extraordinary flexibility while maintaining high abrasion and weather resistance. It is not damaged by various solvents and lubricants. It exhibits good toughness resistance, good shock, vibration and shock damping properties, which are of great importance in the field of conveyors. This material is also suitable for mixing with other polymers, such as ABS or PMMA. Increasingly often, you can also come across new material solutions for elastic bands. This primarily includes composite belts. Such conveyor belts are widely used in industry for transporting products using negative pressure [1,10-15]. The material diversity of the elastic belts themselves indicates the resulting problem of fastening belts. Due to the fact that each conveyor belt has different mechanical properties, the method of connecting them is a very important aspect.

Conveyor belts can be connected in three main ways: vulcanized (weldable or heatweldable), glued or mechanically. The latter are used because of the ease of assembly and the possibility of detaching the ends of the belt, e.g., for cleaning the belt. Mechanical fasteners have different durability, depending on many factors. The reason for the reduction of strength or destruction of the mechanical fastener may be excessive loads, fatigue phenomena of the ends of the joined belts or mechanical elements, abrasive wear of metal elements, corrosion or improper execution of the connection. The strength of mechanical connections of conveyor belts is a complex issue due to the variety of materials (materials and structure of the belt and the metal part of the connection) and the load states in the joints. The aforementioned forces that transmit the elastic bands are related in a specific way to the mechanical connections and their properties, or rather to the load-bearing capacity. The relative strength of the mechanical connection of the belt must be at least $50 \%$ of the belt's nominal breaking strength during transport of spoil. The presented connections are especially suitable for elastic fabric-rubber bands without a core made of steel ropes, but also other ones, such as, for example, made of TPU. The connections are designed to be compatible with the standard widths of the manufactured conveyor belts.

Based on the literature [16-20], an initial analysis of the distribution of stresses propagating in the belt conveyor system was performed (Figure 1). It shows a general scheme of the structure of a belt conveyor with the use of a elastic belt and a mechanical fastener, in which the following can be distinguished: 1 -mechanical fastener, 2-drive roller, 3-return idler, 4-elastic belt, and 5-tensioning roller (return roller).

A condition of the operation mode of the conveyor without belt slippage is (1). The $\mu$ is the coefficient of friction between the conveyor belt and the roller.

$$
\frac{S_{1}}{S_{2}}=e^{\mu \alpha}
$$

From the calculus of vectors, it follows that (2).

$$
P=S_{1}-S_{2}
$$

After transforming (2) and inserting it into Formula (1), the following result was obtained.

$$
S_{2}=\frac{P}{e^{\mu \alpha}-1}
$$


The force in the upper bend can be calculated from the dependence (2). The value of the resultant force $Q$ loading the shaft was calculated using the famous cosine law (4).

$$
Q=\sqrt{S_{1}^{2}+S_{2}^{2}+2 S_{1} S_{2} \cos \delta}
$$

Figure 2 shows detail B in Figure 1, thanks to which it is possible to calculate the inclination angle $\theta$ of the resultant force vector $Q$, which is needed to decompose this force into a vertical and a horizontal component $Q_{x}$ and $Q_{y}$.

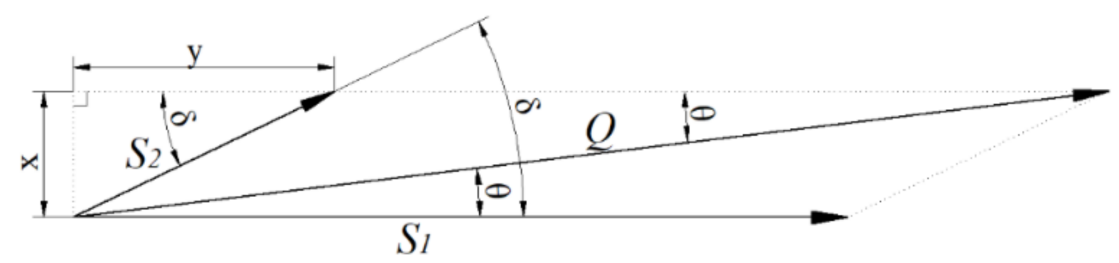

Figure 2. Scheme for calculating the inclination angle $\theta$ of the resultant force vector $Q$.

Two auxiliary parameters $x$ and $y$ were introduced, and the angle $\theta$ was calculated using trigonometric functions (5) and (6).

$$
\begin{gathered}
x=S_{2} \sin \delta ; y=S_{2} \cos \delta \\
\tan \theta=\frac{x}{S_{1}+y}=\frac{S_{2} \sin \delta}{S_{1}+S_{2} \cos \delta} \\
\theta=\tan ^{-1}\left(\frac{S_{2} \sin \delta}{S_{1}+S_{2} \cos \delta}\right)
\end{gathered}
$$

The calculation of the resultant force loading the main shaft is important in the context of this work, because, as it will turn out in a moment, the mechanical connection generates additional forces that also load the shaft.

Figure 3 shows detail A from Figure 1. This detail is presented in two specific phases of the conveyor's work cycle-on the left: at the moment of contact of the contact edge, the mechanical connection with the cylindrical surface of the roller (during the run-up on the roller); on the right: when the face of the mechanical connection is tangent to the cylindrical surface of the roller (while circling the roller). This shows in a simplified way the distribution of stresses resulting from the application of a mechanical connection.
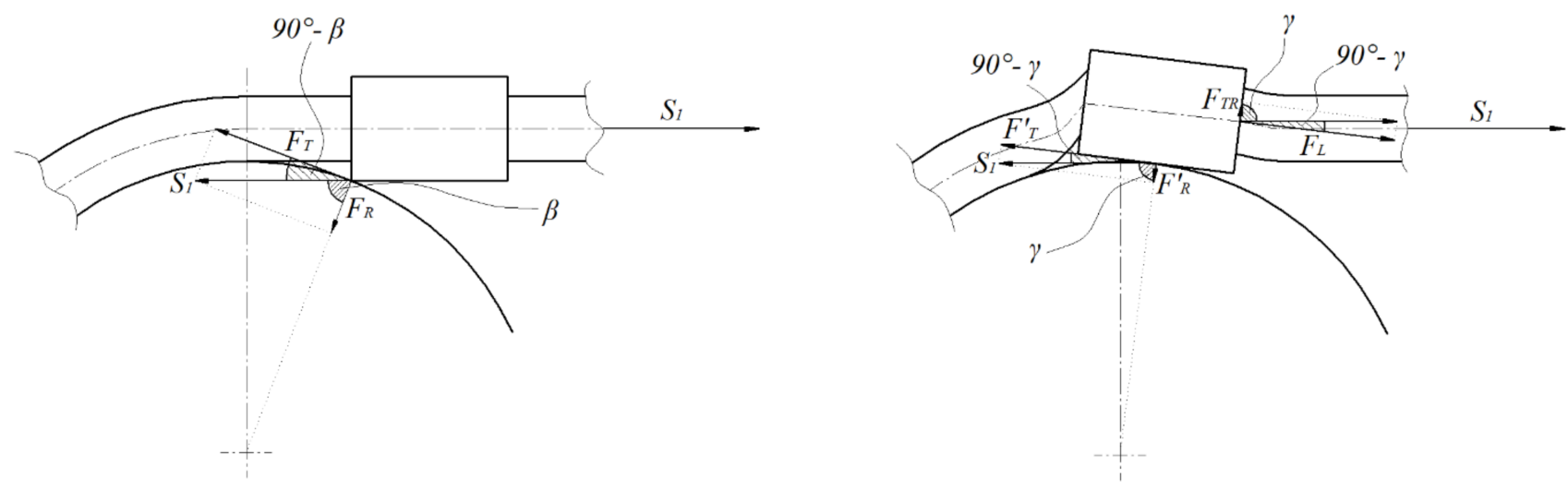

Figure 3. Stress distribution in the roller-belt-mechanical fastener configuration during: (left) ramp-up, (right) circulating around the roll. Explanations: $F_{R}$-radial force during the run-up, $F^{\prime}{ }_{R}$-radial force while going around the roller, $F_{T}$-tangential force during the run-up, $F^{\prime}{ }_{T}$-tangential force while going around the roller (which is the same as the friction force on the bottom surface of the joint), $F_{T R}$-transverse force, $F_{L}$-longitudinal force. 
When the joint is pushed onto the roller (at the moment of contact), the mechanical fastener acts with a force $S_{1}$ on the cylindrical surface of the driving roller. By distributing this force into two components, a radial force $F_{R}$ was obtained, which additionally (apart from the $Q$ force) loads the main shaft, and the tangential force $F_{T}$. This phase is a kind of impulse/shock impact of the joint against the roller, and it is during this phase that the radial load is the greatest. As the joint circulates around the drive roller, the distribution of forces is similar, except that now the tangential force $F_{T}$ is at its greatest value. Some dependencies can be noticed (7).

$$
\left|F_{T}^{\prime}\right|=\left|F_{L}\right| ;\left|F_{R}^{\prime}\right|=\left|F_{L}\right|
$$

Figure 4 also shows detail A from Figure 1, but this time in cross-section. It shows an example of a mechanical joint and the forces acting on it. The connecting element can be, for example, either a screw or a rivet. The previously derived forces that load the joint are: $F_{T R}$ - transverse force, which generates tensile of the core of the link (bolt/rivet, etc.) and bending of the plate of the mechanical joint; and $F_{L}$-longitudinal force, which generates a shear cross section of the link.

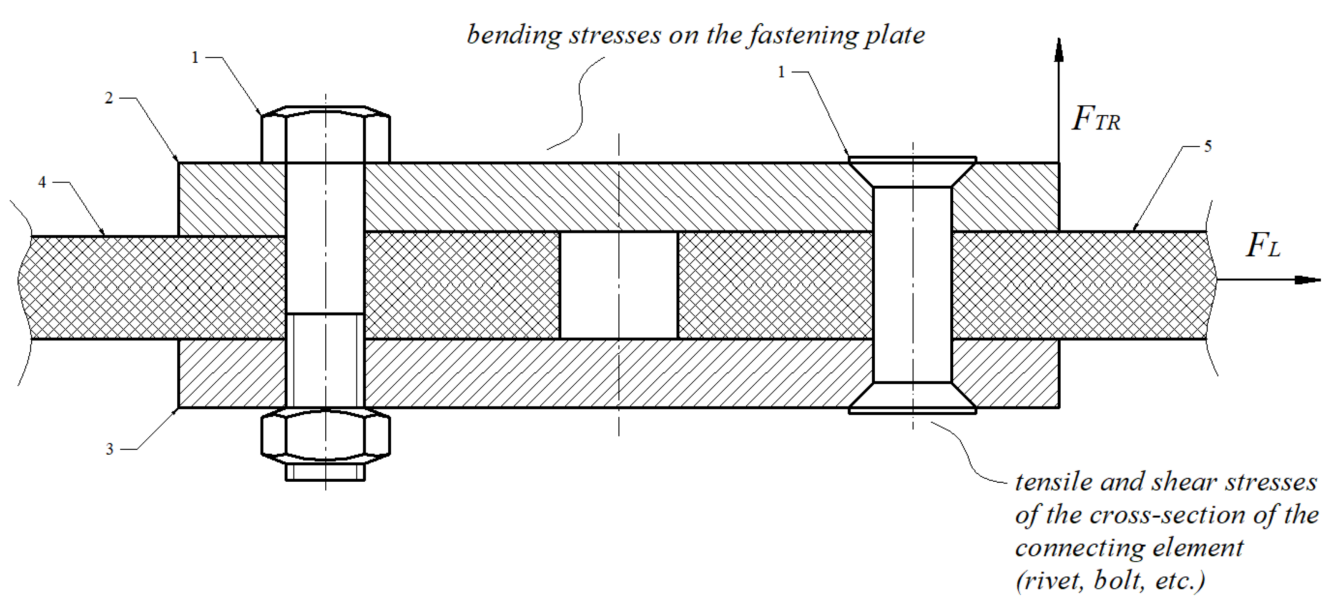

Figure 4. Cross-section of the fastener showing the forces loading the components of the mechanical fastener itself. Explanations: 1-connector/link, 2-upper joint plate, 3-lower joint plate, 4-one end of the conveyor belt, 5 - the other end of the belt.

An article was found [21] in the available scientific databases that was helpful in the process of choosing the right mechanical connection of flat conveyor belts; however, the development of their design and the use of more and more complex materials for the belts determine the need for a deeper study of this issue. In the second part of this work, a detailed review of existing commercial mechanical joint solutions was carried out to establish the state of knowledge and technology and the state of ignorance. In the summary, an algorithm and special design maps were generated to facilitate the process of selecting the right connection. Several design aspects were also derived to provide the basis to analyze differences between individual mechanical connections as they have different properties and are suitable for different applications. Each of these aspects will be considered individually in the context of further research in the search for a customized design solution.

One of the key parameters in the selection of a mechanical connection is the minimum roller diameter. However, it is not obvious why this is so important. The argument below shows that it is indirectly related to the forces that arise, but the source is only the geometric values. On the basis of conversations with industrialists, information was obtained suggesting that often, even when the required minimum diameter of the connection roll is used, the belts-e.g., staples—-become detached. The two arrangements of the roller with the belt and staple fastener are compared below. 
The starting point is the assumption of common and identical output parameters. As a conveyor constructor, I want to check what the model of the roller-belt-connection system looks like using two extremely different roller diameters. In this case, the linear speed of the belt must remain the same in both systems, because we want the load to move at a given speed.

$$
v_{1}=v_{2}=v
$$

The length of the conveyor was set the same.

$$
L_{1}=L_{2}=L
$$

The width of the belt also remains the same.

$$
B_{1}=B_{2}=B
$$

The arrangement of the driving roller and the return roller of the same diameter and the horizontal arrangement were adopted. Therefore, the angle of contact in both systems will be the same and equal to 180 degrees.

$$
\alpha_{1}=\alpha_{2}=\alpha
$$

Then, the same friction lining was applied to the rollers in both systems and the same belt. Therefore, the friction coefficient will be the same.

$$
\mu_{1}=\mu_{2}=\mu
$$

Therefore, it was concluded that the force ratio in the upper and lower strand must remain the same in both systems. However, does that mean the forces will be the same? This cannot be clearly stated yet.

$$
\frac{S_{1-I}}{S_{2-I}}=e^{\mu \alpha} ; \frac{S_{1-I I}}{S_{2-I I}}=e^{\mu \alpha}
$$

consequently

$$
\frac{S_{1-I}}{S_{2-I}}=\frac{S_{1-I I}}{S_{2-I I}}
$$

As the two rollers will have different diameters, they will also have different rotational speeds. For a larger roller:

$$
n_{I}=\frac{60,000 \cdot v}{\pi \cdot D}
$$

For a smaller roller:

$$
n_{I I}=\frac{60,000 \cdot v}{\pi \cdot d}
$$

In this connection, where

$$
D>d
$$

the following is true

$$
n_{I}<n_{I I}
$$

In the so-called basic method for calculating belt conveyors [1,22,23], the circumferential force on the roller in steady motion is equal to the total motion resistance.

$$
P=W_{C}
$$

Total resistance to motion $W_{C}$ consists of several parts

$$
W_{C}=W_{G}+W_{S}+W_{D}
$$


The main resistances $W_{G}$ are calculated from the formula

$$
W_{G}=\mu \cdot L \cdot\left[m_{k}^{\prime}+\left(2 \cdot m_{t}+m_{l}^{\prime}\right)\right] \cdot g
$$

The parameter $m_{k}^{\prime}$ is the mass of the rotating parts of idlers per one meter of the conveyor length. Due to the fact that in both systems the belt length will be the same and the number of upper and lower idlers will be the same, the weight of the rotating elements will also be the same.

$$
m_{k-I}^{\prime}=m_{k-I I}^{\prime}=m_{k}^{\prime}
$$

The parameter $m_{t}$ is the weight of the belt per one meter of the conveyor length, which is related to the weight of the belt support covers. Due to the use of the same belt in terms of thickness, width and material, this parameter will be the same in both systems

$$
m_{t-I}=m_{t-I I}=m_{t}
$$

The parameter $m_{l}^{\prime}$ is the mass of spoil loading one meter of the conveyor belt, which is related to the efficiency and linear speed of the belt. We have the same speed in both systems, and we want to achieve the same efficiency; therefore, this parameter also remains the same.

$$
m_{l-I}^{\prime}=m_{l-I I}^{\prime}=m_{l}^{\prime}
$$

The parameter $\mathrm{g}$ is the acceleration of gravity; therefore, it was finally found that the main resistances of motion in both systems are the same in terms of their value.

$$
W_{G-I}=W_{G-I I}=W_{G}
$$

Concentrated resistances $W_{S}$ are determined using the formula below

$$
W_{S}=(C-1) \cdot W_{G}
$$

Concentrated resistances are caused primarily by inertial forces and frictional forces occurring in the area of the loading point. The $C$ factor in this case depends on the length of the conveyor, which is the same in both systems. Therefore, concentrated resistances have the same value.

$$
W_{S-I}=W_{S-I I}=W_{S}
$$

Additional resistances $W_{D}$ are caused by the use of a special device in the conveyor (e.g., scraper, rollers ahead, etc.). Therefore, it can also be assumed that in both systems these resistances have the same value.

Ultimately, therefore, it can be concluded that the total resistance to movement in both systems, despite the use of a different roll diameter, are the same in terms of value.

$$
W_{C-I}=W_{C-I I}=W_{C}
$$

Consequently, the circumferential force in both systems remains the same, and thus the forces in the tendons are also the same.

$$
P_{I}=W_{C} ; P_{I I}=W_{C}
$$

and so

$$
P_{I}=P_{I I}=P
$$

in that case

$$
S_{2-I}=\frac{P}{e^{\mu \alpha}-1} ; S_{2-I I}=\frac{P}{e^{\mu \alpha}-1}
$$

and so

$$
S_{2-I}=S_{2-I I}=S_{2}
$$


and

$$
S_{1-I}=S_{1-I I}=S_{1}
$$

In connection with the above argumentation, the question arises: why is a minimum diameter of a roller required, if the forces in the tendon remain the same? The answer is shown in Figure 5. Due to the use of a smaller roller, the opening angle between the two hinge plates is greater. As a consequence, the vector of the perpendicular force acting on the plate is larger. Therefore, the essence is only the geometry.

(a)
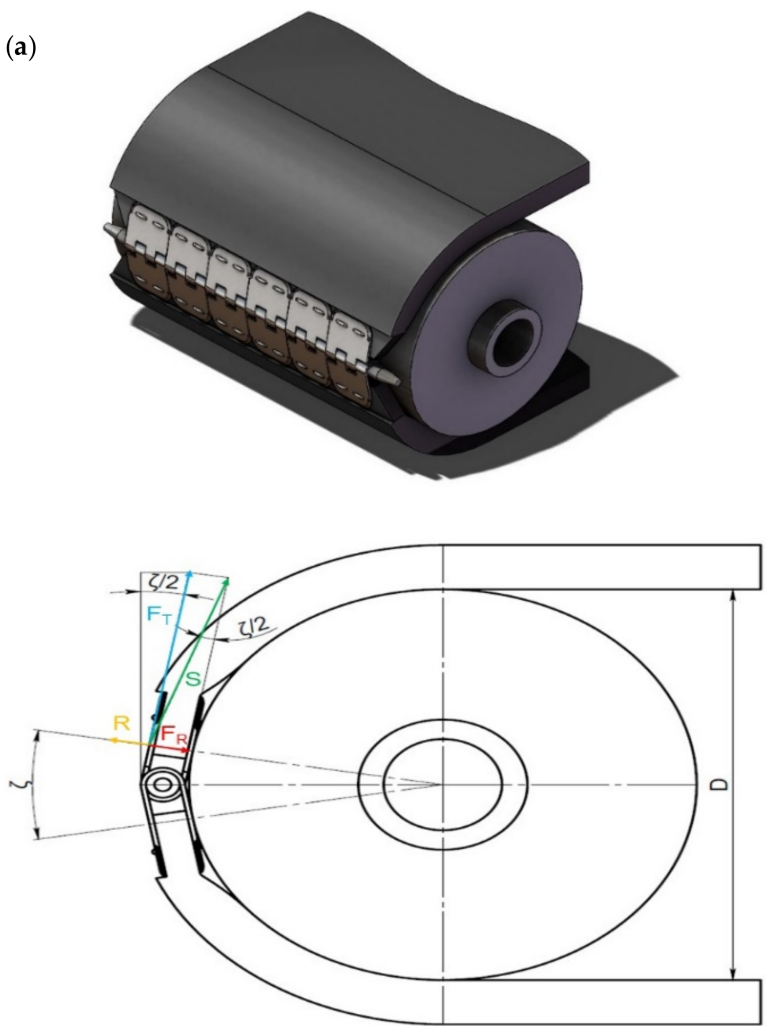

(b)
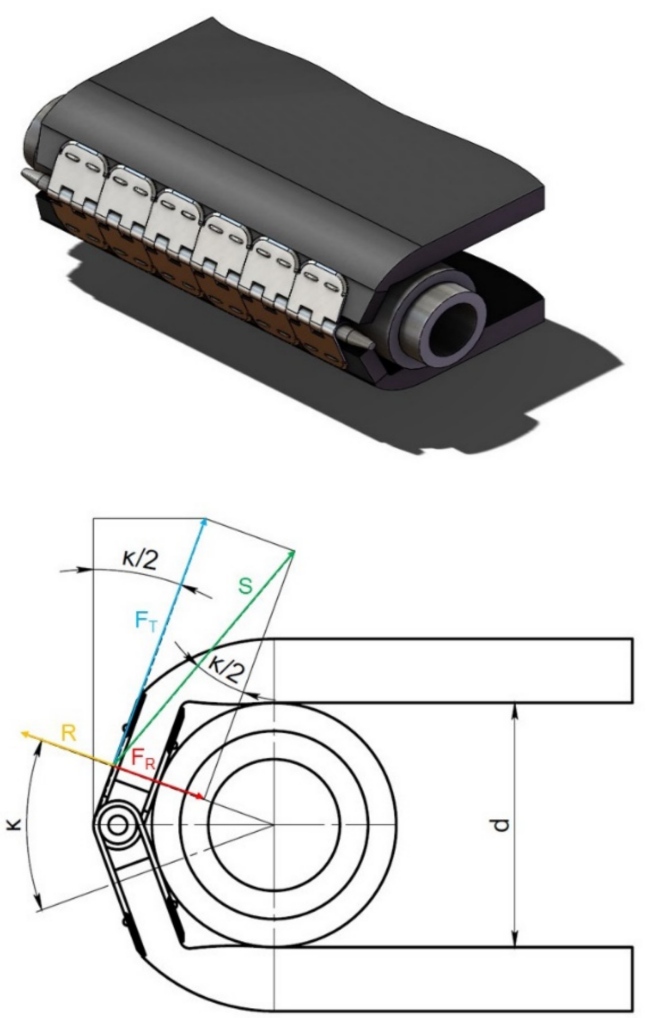

Figure 5. Drawing summarizing the analytical evidence that the minimum roll diameter requirement in the context of two conveyor systems with the same loading parameters is in fact a geometric problem: (a) a larger diameter roll, (b) a smaller diameter roll. Explanation: $\zeta$-opening angle of the hinge connection plates in the arrangement with the larger roller, $\kappa$-opening angle of the hinge connection plates in the arrangement with the larger roller, $D$-larger diameter, $d-$ smaller diameter, $S$-force in the tendon (green), $F_{T}$ 一tangential force (blue), $F_{R}$-radial force (red), $R$-the force of reaction (yellow) that actually causes the staples to detach from the joint.

Based on a diligent review of the literature, both academic, didactic and researchoriented, contained in the various available scientific databases, no activities have been found to date that study the presented mechanical connections. These issues are dealt with by producers; however, the results of their research activities are secret and not available for inspection. Therefore, the subject matter discussed in this article represents an area of ignorance, and this work is to fill the empty space in this field.

The above preliminary analysis of the stress distribution in the exemplary connection was performed. Of course, this distribution will be presented in further detail in the research process of connections, also with the use of systems operating with the finite element method. There will also be more variants of the distribution of forces, as each connection is characterized by a different structure. A mathematical proof was also drawn because of the necessity of taking into account the minimum diameter of the roller, which is one of the three key parameters when choosing the right joint. A cross-sectional overview of most of the possible alternatives in flat belt connection is provided below. Mainly-for the sake of this work-in the context of creating an algorithm and special design maps to 
assist in choosing the right joining, but also-for future work-in relation to the various design aspects listed in the summary. This was to lay the groundwork for future detailed research. It is expected that the final stage of activities in the field of this topic will be the development of a mathematical model that will allow to design an optimal mechanical connection for the given output parameters in terms of construction.

\section{Solution Overview}

Existing commercial mechanical connection solutions are presented in this section. Several similar solutions have been implemented by several suppliers simultaneously. If such a situation applies to a given mechanical connection, the paper presents only one proposal from the leading manufacturer. The review is based on catalogs, brochures and information from manufacturers' websites [24-26]. Each time, the most important properties of the connection are presented here in tabular form, such as the thickness of the belts to be used, the minimum diameter of the drive roller, mechanical strength (ability to transmit longitudinal loads), operating temperature spectrum, types of resistance, connection material, material of the belts used, and many more. Then the installation method and the general construction of the fastener are briefly described. Each fastener is also presented graphically.

\subsection{Hinge Fastener with a Patch Welded to a Monolithic Belt}

Many manufacturers offer monolithic conveyor belts made entirely of one material -flexible plastic. In this variant, special mechanical lace with patches is used. These patches-made of identical material to the material of the conveyor belt-are welded together with the belt. An example of such a connection is shown in Figure 6. Mechanical lace is a fastener in the form of patches with holes through which the hinge pin passes. By removing this pin, the connection can be easily detached. The pin can be plastic or metal. The patches are made of the same material as the belt-aramid-reinforced thermoplastic polyurethane (TPU). There is no combination of elements in this type that penetrate the belt material, which would weaken the belt structure. The solution is not very universal, and it is difficult to compare it with other solutions due to the possibility of application only in the monolithic series belts. A special series heat press with control unit is required for installation. It does not need water for cooling and there are no exposed hot parts. The size of the press depends on the width of the belt. Joining cycle of the heat press make the thermoplastic joining is performed automatically. The manufacturer ensures that the weld itself is stronger than the hinge mechanical joint. In the context of future research related to the optimal design features for mechanical connections of flat belts, the hybrid method of connection deserves attention. There are no elements penetrating the belt material, and the joint itself is applied by welding. Of course, this is only possible due to the specificity of TPU. However, the problem may be the difficulty of removing the hinge pin and-as the manufacturer himself points out-the possibility of dirt accumulating in the connection holes. It is anticipated that when a plastic hinge pin is used, the first element that will fail will be that pin (unless the material of the pin is stronger than that of the fastener).

There is one more solution - the same, but with a special stick. An example is shown in Figure 7. This solution-just like the previous one-is a fastener in the form of patches with holes through which the hinge pin passes. The difference is that this has special sticks with a non-slip surface. These sticks are coupled with hinge pins and make it easy to detach the tapes. Disconnecting is so simple that when using the fastener, the belt can be cleaned after it is removed from the conveyor. The stick is made of monolithically small dowel pins that go into the holes in the fitting. In this way, the spontaneous disconnection of the mechanical connection is ensured. The construction is also-compared to the Mechanical Lace-more compact, so there is no risk of dirt getting into the connection holes. This effect was achieved by reducing the clearances to a minimum between individual connection elements. A special heat press is also required for installation. In the context of future research, the hybrid connection system used here will also be considered. Summarizing 
both proposals briefly, in the future the authors will try to extend the applicability of such a hybrid combination also to other belts, not only those from the Cleandrive $\mathrm{T}^{\mathrm{TM}}$ series. The problem-also in the case of Mechanical Lace-is the shape of the corner that creates the fastener. This will have a negative impact on belt deflection during operation, as pulleys are not compatible with this connection. This also generates another problem-the impossibility of using a relatively small diameter pulley (compared to other solutions for mechanical joining of flat belts, which are presented later in this work).
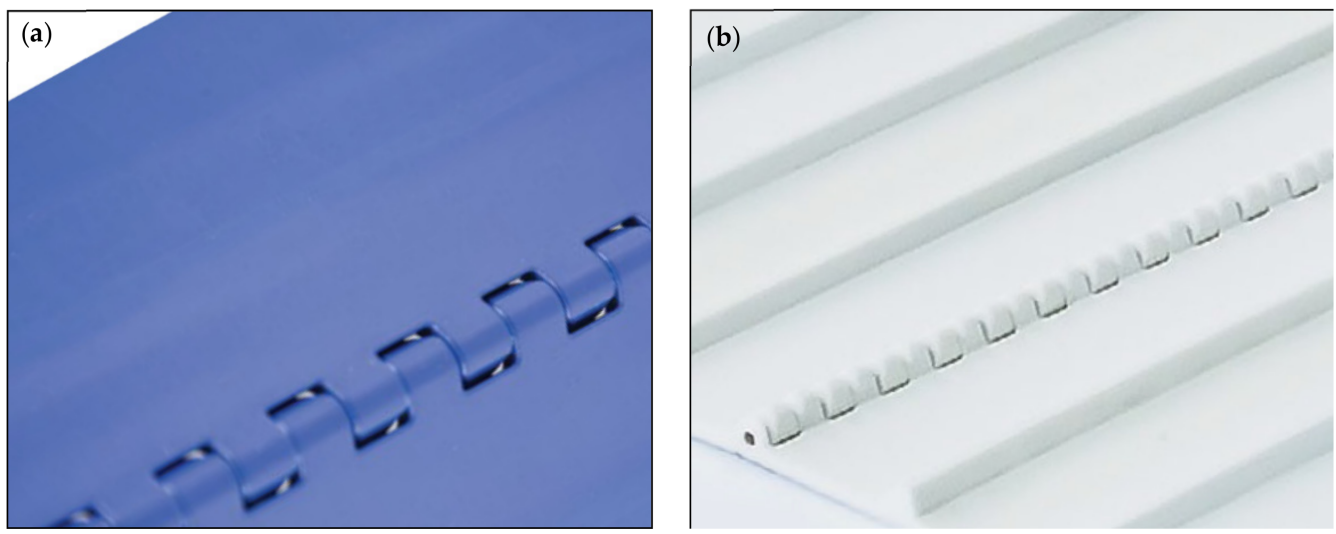

Figure 6. Mechanical Lace: (a) fastener in cobalt blue, size 1"; (b) fastener in white, size 2" [24].
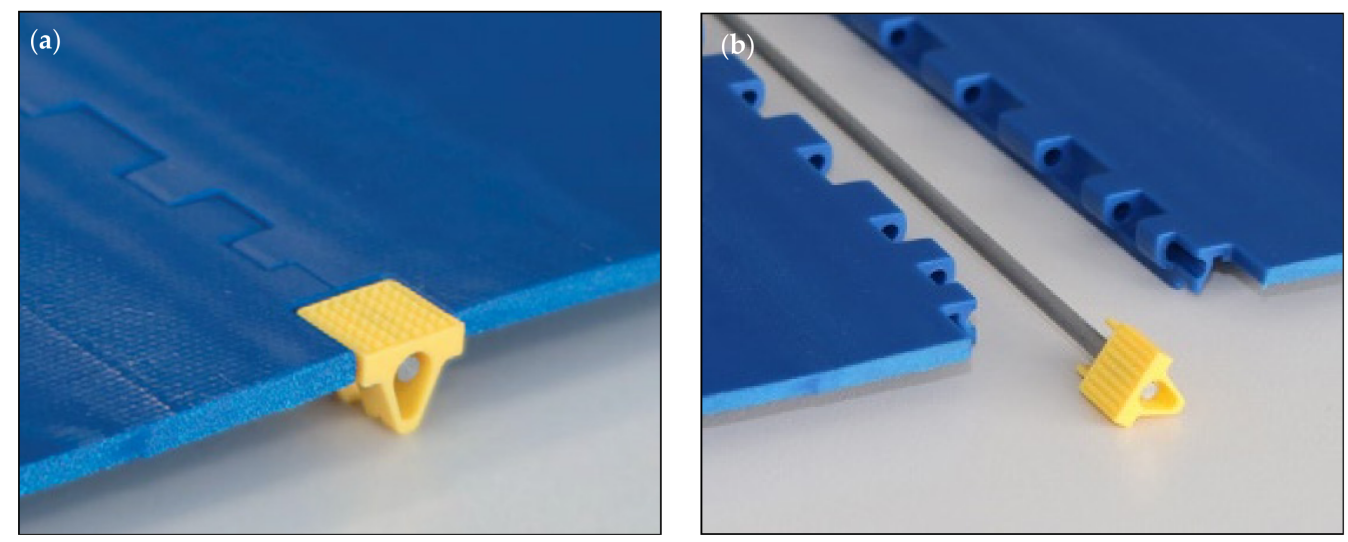

Figure 7. SaniClip: (a) general view, (b) hinge pin connected to a yellow stick [24].

\subsection{Hinge Plate Fastener with Staples Attachment Method}

An example is shown in Figure 8. Intended for joining light and medium-duty synthetic carcass belting. The applications that this fastener can be used in include package and parts conveying, food and sanitary contact, agricultural harvesting and handling, recycling and scrap handling, and wood products. The fastener in this case is a bent plate in which the hinge pin is finally mounted. Two large and thick staples are also pre-embedded here. Single fasteners are available as continuous strips consisting of several fasteners. Extended plate design separates the point of fastener penetration from the line of belt flexing to eliminate splice fatigue at the point of belt attachment. Table 1, below, shows what the fasteners are resistant to, depending on the material made. 

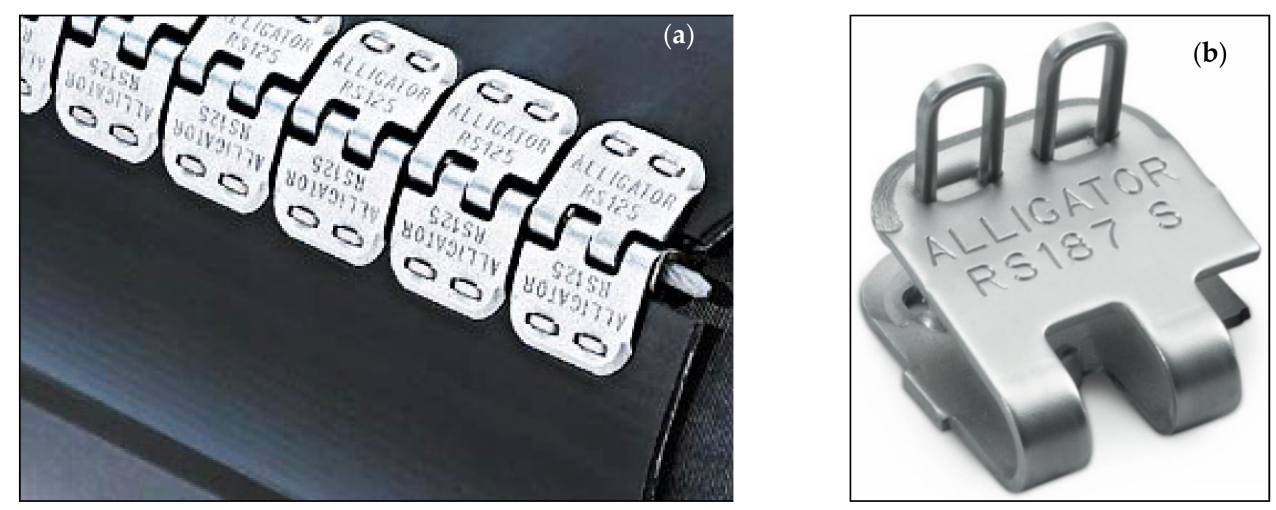

Figure 8. Staple fastening: (a) general view; (b) single fastener [25].

Table 1. Fasteners resistant ranging from one plus sign $(+)$ to four plus signs $(++++)$ [25].

\begin{tabular}{ccccc}
\hline Material of Fastener. & Magnetic & $\begin{array}{c}\text { Abrasion } \\
\text { Resistant }\end{array}$ & $\begin{array}{c}\text { Chemical } \\
\text { Resistant }\end{array}$ & $\begin{array}{c}\text { Rust } \\
\text { Resistant }\end{array}$ \\
\hline Galvanized Steel & No & +++ & + & ++ \\
316 Stainless Steel & Yes & +++ & +++ & ++++ \\
430 Stainless Steel & No & +++ & ++ & +++ \\
MegAlloy & No & ++++ & + & + \\
\hline
\end{tabular}

Hinge pins made of various materials and designed for different applications-Table 2.

Table 2. Hinge pins various materials and different applications [25].

\begin{tabular}{cccl}
\hline Material of Pin & Type of Fastener & Recommended for & Picture \\
\hline NC-Nylon Covered & steel & $\begin{array}{c}\text { for troughing or flat } \\
\text { belt conveyors }\end{array}$ & \\
Steel Cable & stainless steel, & $\begin{array}{c}\text { for extra abrasion and } \\
\text { chemical resistance }\end{array}$ & \\
NCS-Nylon Covered & MegAlloy & & \\
Stainless Steel Cable & ftainless steel & flat belts only & \\
SS-Stainless Steel & & in abrasive or gritty & \\
Spring Wire & steel & material applications & \\
SP-Steel Spring Wire & &
\end{tabular}

Staples are hammer driven through the fastener and belt, working between the carcass fibers without severing them. The staples are then clinched cross-wise to the belt, so that belt tension does not pull against the staples to unclinch them. This is how the fastener is installed manually. Special installation tools are needed. For even better mounting, a system with a pneumatic rammer can be used. To ensure a low-profile connection - compatible with the thickness of the belt-unfortunately, the belt needs to be pre-cut so that the chamfered connection plates can be flush with the belt surface.

Another design solution is the connection shown in Figure 9. Made of high-tensile plated carbon steel (HLE). This connection is distinguished in the study due to the arrangement of staples-in this design variant, the staples are pre-applied in the holes arranged in a V-shape. The geometric aspect is interesting from a research point of view (with respect to the influence of the arrangement on the stress distribution inside the belt during the conveyor operation). 

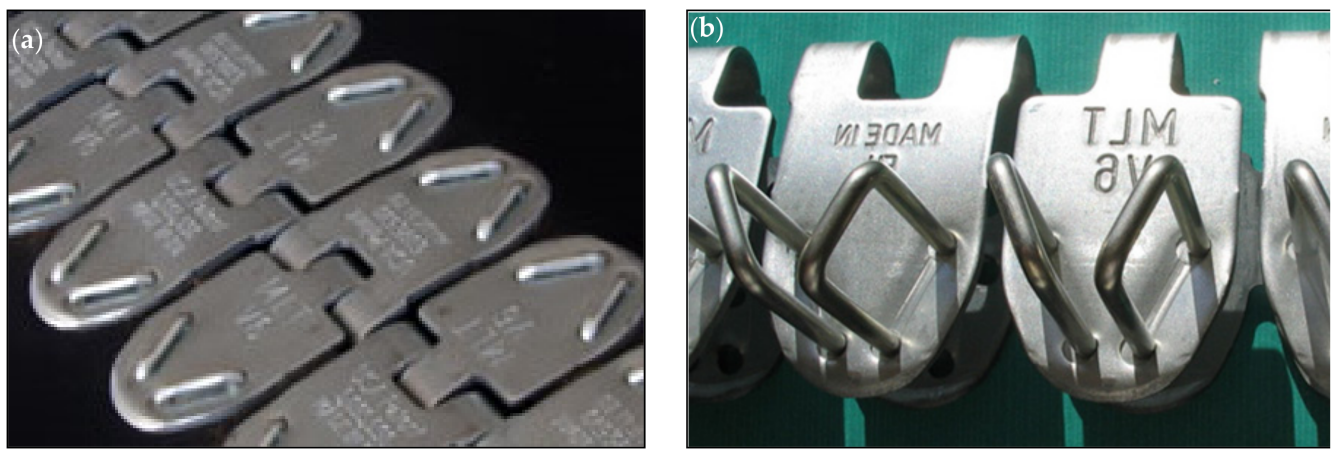

Figure 9. Staple fastening: (a) general view; (b) top view of the fastener [26].

The above two solutions are plate connections, i.e., those in which the hinge elements are in the form of bent plates.

There is also a variation in which, instead of tiles, there are bent wires with flats at the ends. There are gaps in these flats for the staples to pass through. See example in Figure 10. Hinge pins are available in most materials and lagging, as in the previous designs from the same manufacturer. However, for the reinforced series, there are special pins with increased diameter. Their use increases the life of the connection by up to $33 \%$.
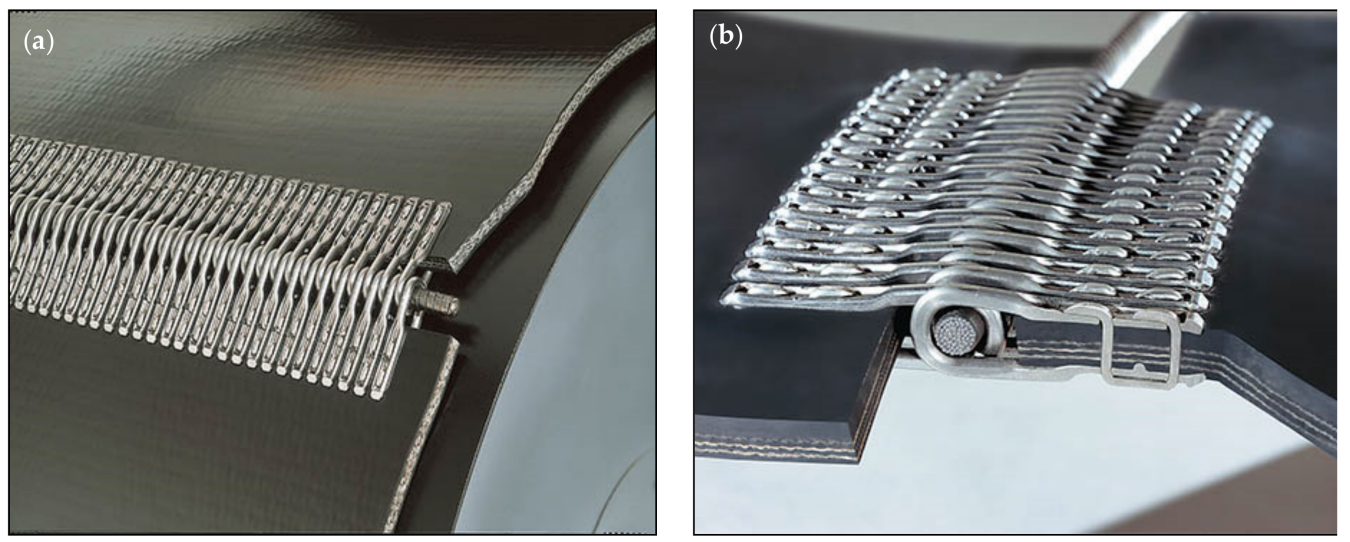

Figure 10. Staple fastening: (a) general view; (b) side view [25].

\subsection{Hinge Fastener with Rivets Attachment Method}

An example is shown in Figure 11. For belts made of PVC, used for food and sanitary contact, and in the electronics industry. The system of fastening, which is made of plastic plates, is also joined with plastic rivets. Available in three different plastic materials-Table 3 .

To install the above-mentioned fastener, you need a special portable device. The rivets are spin set through heat and friction to provide a long-lasting splice.

Another example, this time with metal plates and rivets, is shown in Figure 12. Intended for abusive round hay baling and underground mining. It is a fastener composed of stainless-steel plates with rivets. The assembly uses a handheld device called a portable hand applicator tool kit or a special multiple rivet device installation tool kit with pneumatic mounting. 


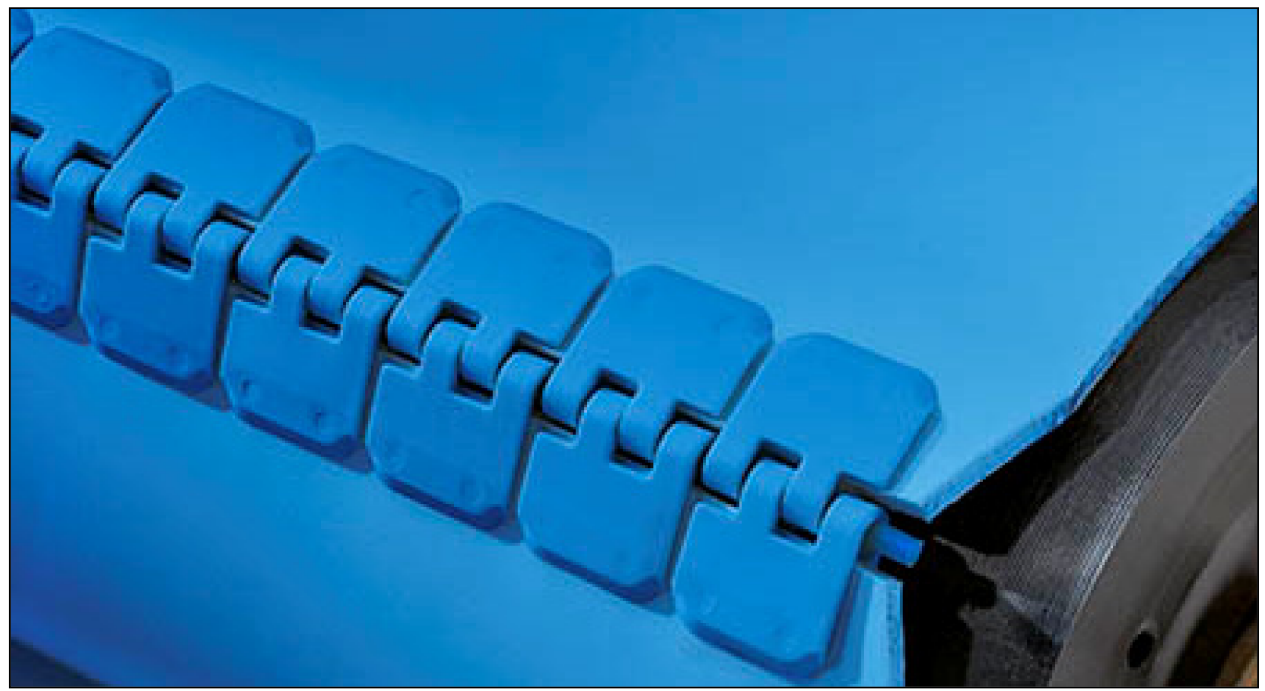

Figure 11. Plastic rivet fastening: general view [25].

Table 3. Material variants of the plastic rivets fastening [25].

\begin{tabular}{cc}
\hline Color & Properties \\
Black & UV-resistant for extended life in outdoor applications \\
White & $\begin{array}{l}\text { FD-accepted material resists weak acids, alkali, } \\
\text { hydrocarbons, ester solvents, and alcohols } \\
\text { FDA-accepted material with the same resistance as the } \\
\text { white offering but colored blue to match blue belts used in } \\
\text { many food applications }\end{array}$ \\
\hline
\end{tabular}
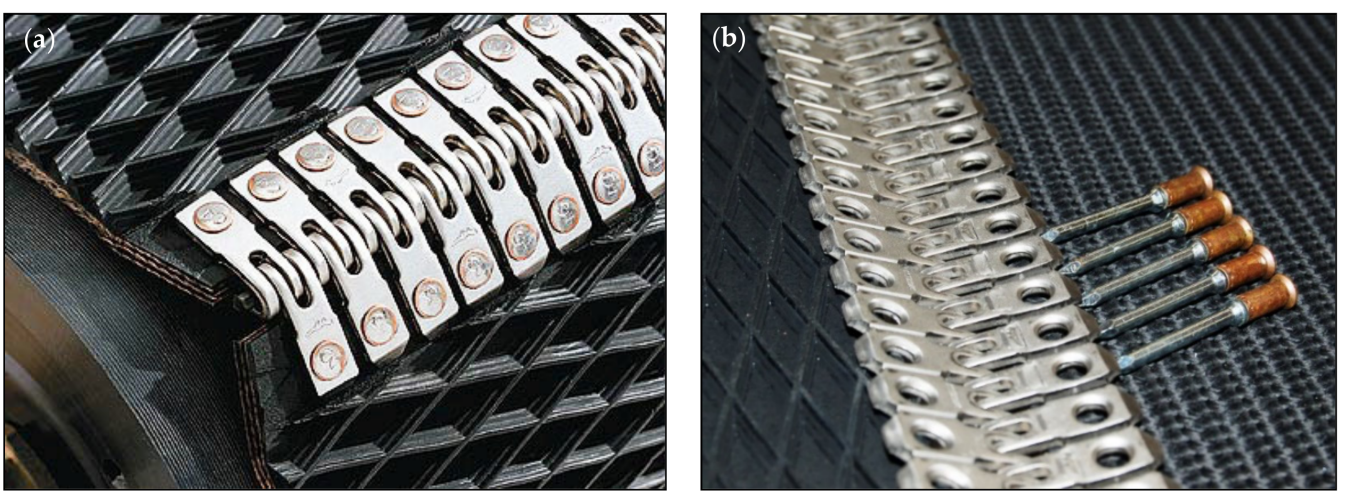

Figure 12. Rivet fastening: (a) general view; (b) individual items [25].

Finally, the strongest of these types of connections is shown in Figure 13. The solution is similar to the previous one, not only in terms of construction (rivets, plates, chamfered), but also in terms of the method of installation and the tools used. This is the most durable combination of all, for really heavy industry: cement, underground and surface mining, crushed stone, coal and hard rock, salt, wood processing, asphalt plants. Table 4 below shows what the fasteners are resistant to, depending on the material made. 


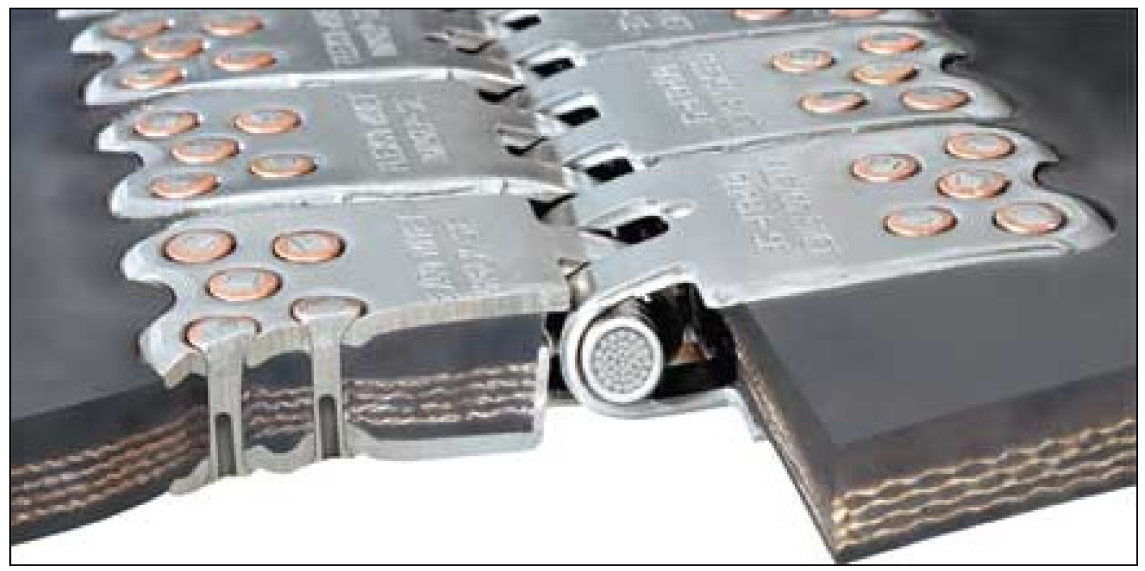

Figure 13. Rivet fastening: cross section view [25].

Table 4. Fasteners resistant ranging from one plus sign $(+)$ to four plus signs $(++++)$ [25].

\begin{tabular}{ccccc}
\hline Material of Fastener & Magnetic & $\begin{array}{c}\text { Abrasion } \\
\text { Resistant }\end{array}$ & $\begin{array}{c}\text { Chemical } \\
\text { Resistant }\end{array}$ & Rust Resistant \\
\hline Galvanized Steel & Yes & +++ & + & ++ \\
300 Stainless Steel & Slightly & +++ & +++ & ++++ \\
MegAlloy ${ }^{\circledR}$ & Yes & ++++ & + & + \\
RustAlloy & Yes & +++ & +++ & +++ \\
\hline
\end{tabular}

Hinge pins can be made of various materials. Details are presented in Table 5, where the middle column shows the application for a given hinge pin.

Table 5. Hinge pins various materials and different applications [25].

\begin{tabular}{|c|c|c|}
\hline Material of Pin & Applications & Picture \\
\hline AC-Bar Armored Cable & $\begin{array}{l}\text { Heavy-duty, longwearing pin popular in underground mining } \\
\text { applications. Armor wrapping protects interior wires. }\end{array}$ & \\
\hline ACS_Bar Armored Stainless Cable & $\begin{array}{l}\text { The same advantages as bare armored cable plus } \\
\text { corrosion resistance }\end{array}$ & 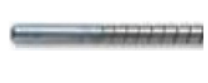 \\
\hline NAC-Nylon Covered Armored Cable & $\begin{array}{c}\text { Combines a durable armored steel wrap with a nylon covering } \\
\text { for smooth operation and long service life. Nylon covering } \\
\text { prevents pin migration. Not recommended in wet, } \\
\text { abrasive applications. }\end{array}$ & $\rightleftarrows$ \\
\hline NC-Nylon Covered Steel Cable & $\begin{array}{l}\text { Nylon covering prevents pin migration. Not recommended in } \\
\text { wet, abrasive applications. }\end{array}$ & $\rightleftarrows$ \\
\hline NCS—Nylon Covered Stainless Cable & $\begin{array}{l}\text { For greater corrosion resistance. Not recommended in wet, } \\
\text { abrasive applications. }\end{array}$ & $\rightleftarrows$ \\
\hline SC_-Bar Steel Cable & Recommended for abrasive or gritty material conveyance. & masessssss \\
\hline SSC_Bar Stainless Steel Cable & For conditions where corrosion attacks steel pins. & 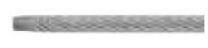 \\
\hline
\end{tabular}

\subsection{Fastener with Bolts/Screws Attachment Method}

An example is shown in Figure 14. For construction and road equipment, coal, salt, potash, grain, wood products, recycling applications. Hinge pins can be made of various materials and designed for different applications. Details are presented in Table 6. 

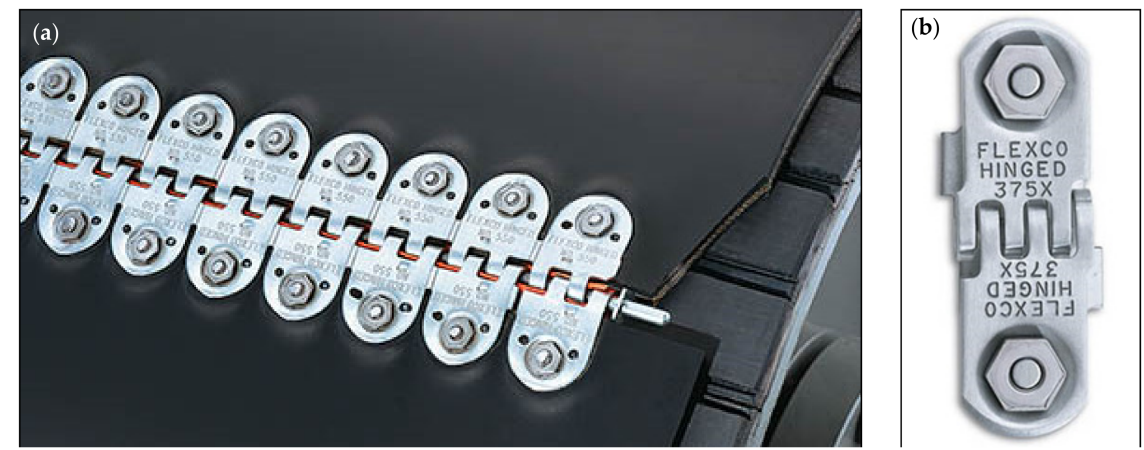

Figure 14. Bolt fastening: (a) general view, (b) single fastener [25].

Table 6. Hinge pin types with regard to the application [25].

\begin{tabular}{cc}
\hline Material of Pin & Recommended for \\
\hline NC-Nylon Covered Steel Cable & reduces corrosion and simplifies hinge pin insertion \\
NCS-Nylon Covered Stainless & greater corrosion resistance \\
Steel Cable & recommended for abrasive or gritty material conveyance \\
SC-Bare Steel Cable & conditions where corrosion attacks ordinary steel pins \\
SSC-Bare 300 Series Stainless & \\
\hline
\end{tabular}

Table 7, below, shows what the fasteners are resistant to, depending on the material made.

Table 7. Fastener Material Characteristics ranging from one plus sign $(+)$ to four plus signs $(++++)[25]$.

\begin{tabular}{|c|c|c|c|c|}
\hline Material of Fastener & Magnetic & $\begin{array}{l}\text { Abrasion } \\
\text { Resistant }\end{array}$ & $\begin{array}{l}\text { Chemical } \\
\text { Resistant }\end{array}$ & Rust Resistant \\
\hline Galvanized Steel & Yes & +++ & + & ++ \\
\hline 300 Stainless Steel & Slightly & +++ & +++ & ++++ \\
\hline MegAlloy ${ }^{\circledR}$ & Yes & ++++ & + & + \\
\hline Everdur & No & + & + & + \\
\hline
\end{tabular}

A special plastic filler tubing (Figure 14a-orange tube) is also used for the connection and keeps sifting of fine materials through the hinged joint to a minimum.

\subsection{Wire Hook Fastener}

An example of such a connection is shown in Figure 15. For belts made of solid woven PVC and can be applied in package and parts handling, general manufacturing, commercial laundry, food processing, agriculture, filter media. Table 8 shows what the fasteners are resistant to, depending on the material made.
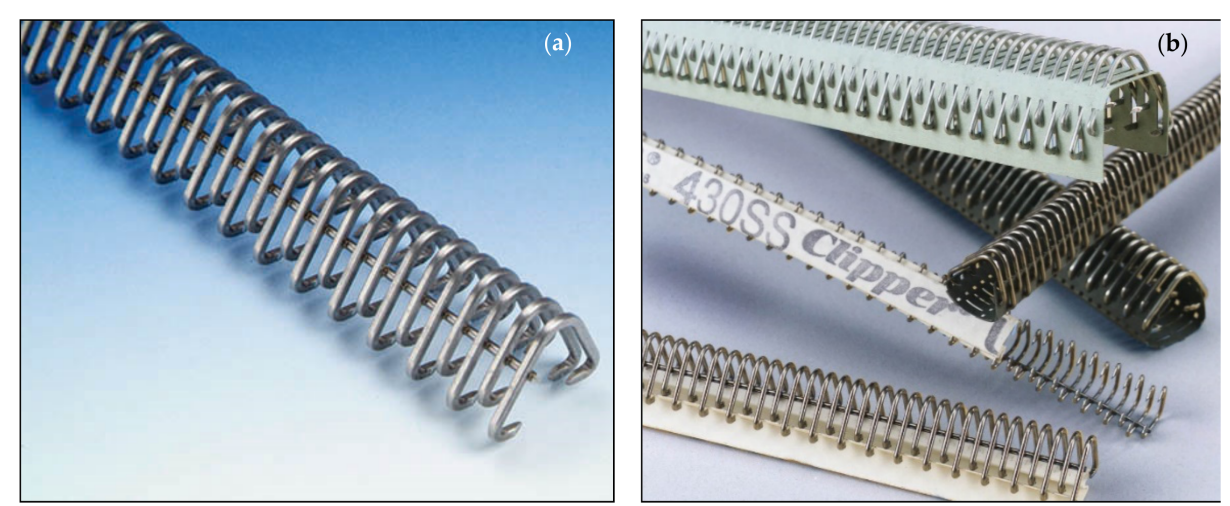

Figure 15. Wire hook fastening: (a) welded to a common rod; (b) carded [25]. 
Table 8. Fastener Material Characteristics ranging from one plus sign $(+)$ to four plus signs $(++++)[25]$.

\begin{tabular}{ccccc}
\hline Material of Fastener & $\begin{array}{c}\text { Magnetic } \\
\text { Resistance }\end{array}$ & $\begin{array}{c}\text { Abrasion } \\
\text { Resistant }\end{array}$ & $\begin{array}{c}\text { Chemical } \\
\text { Resistant }\end{array}$ & $\begin{array}{c}\text { Rust } \\
\text { Resistant }\end{array}$ \\
\hline Galvanized Steel & Yes & +++ & + & +++ \\
Coated Steel ${ }^{\mathrm{TM}}$ /Steel & Yes & +++ & + & +++ \\
High Tensile Steel & Yes & ++++ & ++ & +++ \\
Rectangular High & Yes & ++++ & ++ & +++ \\
Tensile Steel & Yes & +++ & +++ & +++ \\
430 Stainless Steel & Slightly & +++ & ++++ & ++++ \\
316L Stainless Steel & Slightly & ++ & ++++ & ++++ \\
Monel ${ }^{\circledR} 400$ & No & ++ & ++++ & ++++ \\
Inconel ${ }^{\circledR}$ 600 & No & +++ & + & +++ \\
Phosphor Bronze & No & +++ & ++++ & ++++ \\
Hastelloy C-22 & Yes & +++ & + & ++ \\
Black Oxide Steel & & & \\
\hline
\end{tabular}

It is a hook system using different wire diameters and leg lengths. Available with two types of hooks: welded to a common rod (Figure 15a) to increase installation safety and facilitate interlocking of the ends of the straps-and carded fasteners-and single hooks secured on carding paper (Figure 15b) for safe handling. Hinge pins are available in different variants, as shown in Table 9. Installation requires a special tool, which gently and precisely rolls the hooks around the belt.

Table 9. Connecting pin types for the wire hook fastening [25].

\begin{tabular}{ccc}
\hline Material of Pin & Diameter of Pin [mm] (inch) & Picture \\
\hline DuraStainless $^{\mathrm{TM}}$-DSS & $1.7(0.065)$ & \\
Duralink $^{\mathrm{TM}}$-DL & $2.4(0.093)$ & \\
Nylosteel-NY $_{\text {Nylostainless-NYS }}$ & $2.8(0.109)$ & \\
Nylon-Covered-Cable-NCS & $3.2(0.125)$ & \\
Nylon Plus-NP & $4.0(0.156)$ & \\
\hline
\end{tabular}

A smaller variation of such a solution with corrugated Perlon hinge pin-mainly for the laundry industry - is shown in Figure 16. For PVC, PU, cotton and cotton mix tape, and filter belts. This is a double fastening system: by hooks and by adhesive bonding. The individual fasteners are secured in the material of a special patch. During quick assembly, the adhesive is activated by heated jaws. The attachment points are covered with a patch during assembly to prevent hooks from becoming snagged and damage to the belt material. The hooks are integrated into the polyester patch material. The hinge pin that connects both ends of the belt is made of a so-called Perlon. It is anti-corrosive and provides lubrication of the lap joint. Mounting is performed by hand or using a hydraulic mounting tool.

\subsection{Metal Fastener with Legs or Clamp}

A first example is shown in Figure 17. For PVC, PU and PES belts. Application: food manufacturing, filter media, package and parts handling. It is a system with an alternating leg structure with four different leg lengths. It ensures constant compression, and as a result, a flat and uniform connection. The finished lacing is very durable. Made of AISI 316 stainless steel. The flat, continuous top bar design eliminates belt ripple and reduces the risk of fasteners falling out. There is also a double lacing pattern which provides good holding strength without compromising the integrity of the belt structure. Assembly, as in the case of the previous type of fastening, is also performed using a special installation tool. 

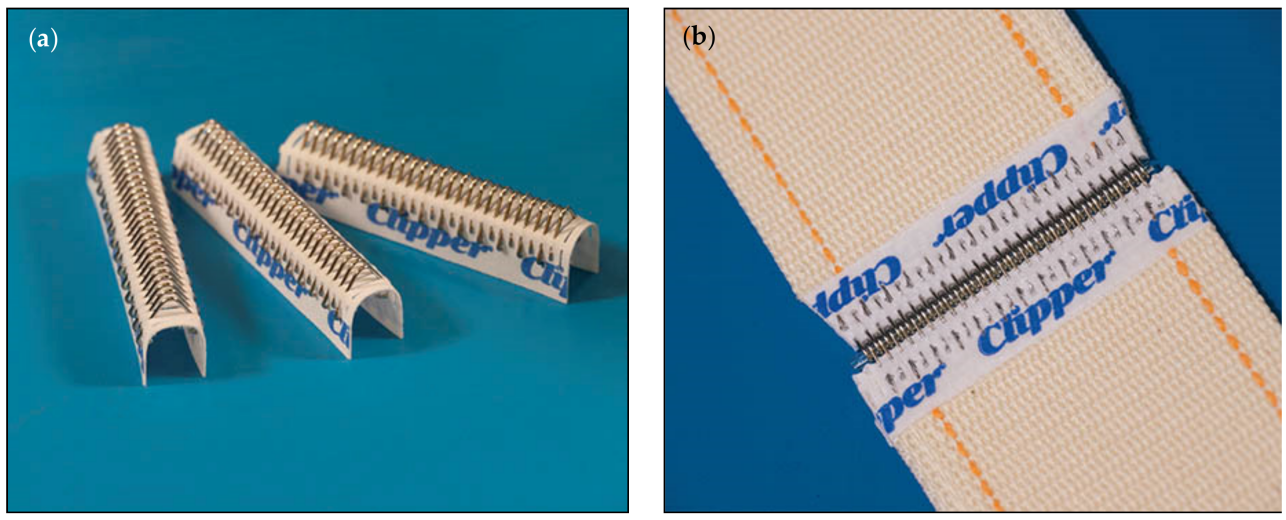

Figure 16. Laundry patch hooks fastening: (a) single fastener, (b) after mounting [25].
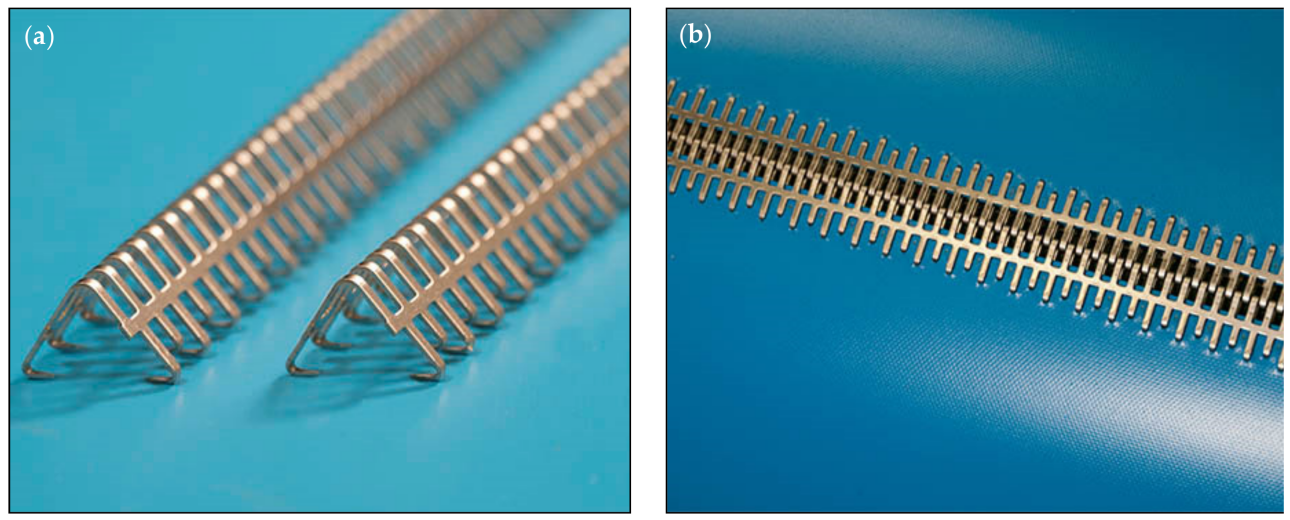

Figure 17. Metal legs fastening: (a) general view; (b) fastener installed on the belt [25].

Another example is shown in Figure 18. This is for rubber-fabric belting. Application: agricultural harvesting and handling, package and parts conveying, food and sanitary contact, recycling and scrap handling, wood products.
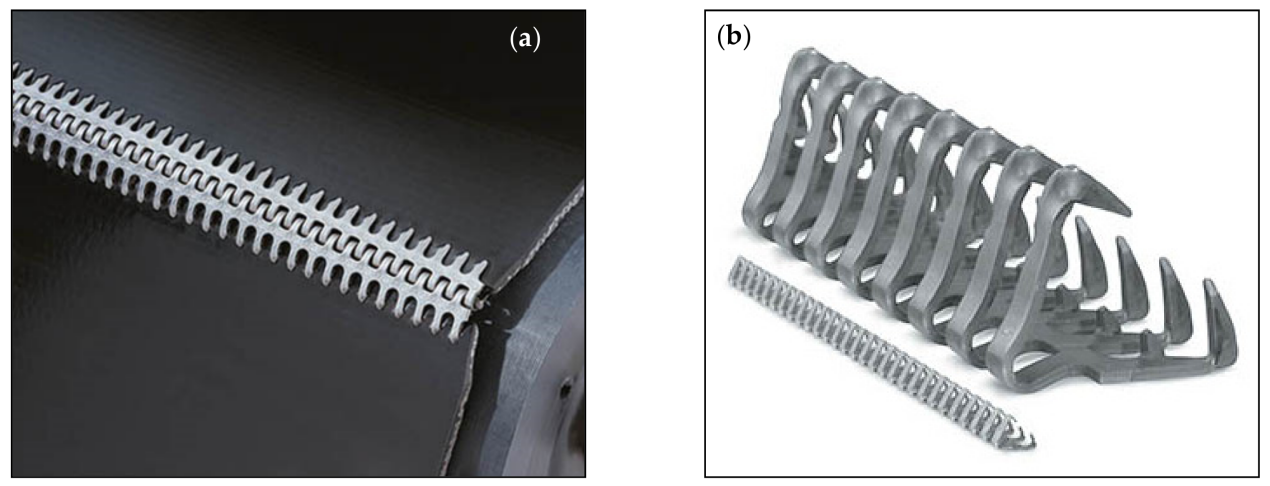

Figure 18. Metal legs fastening: (a) general view on the belt; (b) single string of fasteners [25].

The example in Figure 19 is an even more clever and sophisticated solution. It has double rows of teeth, which has a positive effect on durability. Suitable for work in a trough arrangement. Made of non-magnetic 316L stainless steel. Application for light belts with a thickness of $1 \mathrm{~mm}$ to $5 \mathrm{~mm}$. The minimum diameter of the pulley is from $20 \mathrm{~mm}$ to $75 \mathrm{~mm}$ (depending on the size of the mechanical fastener). A special multitool can be used for installation. The teeth are arranged in a meander pattern. This meander design eliminates risk of losing claws. 

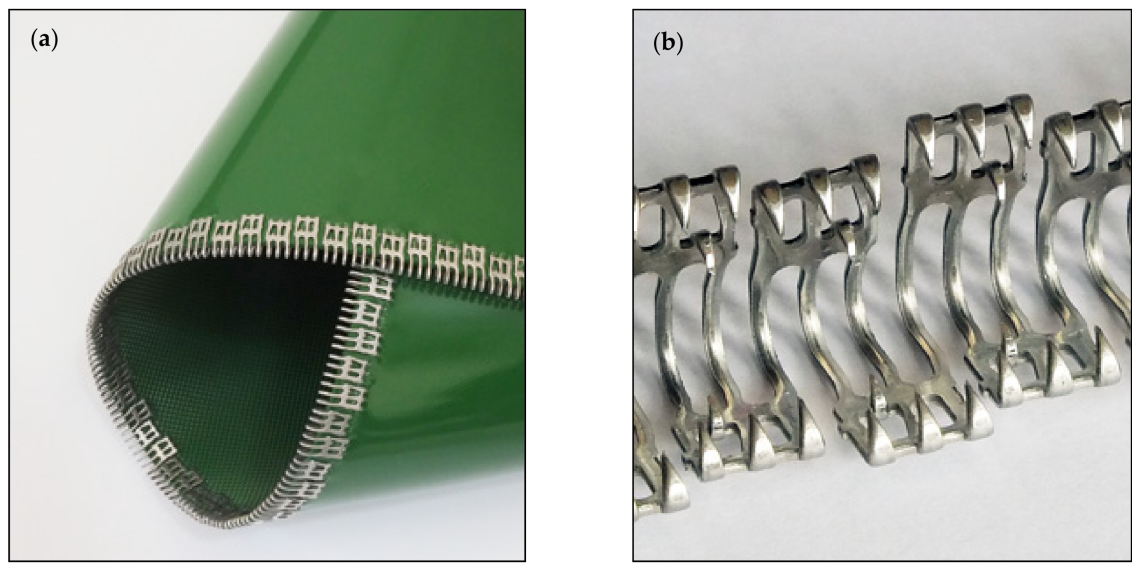

Figure 19. Metal teeth fastening: (a) general view; (b) single string of mechanical fasteners [26].

Another design solution is the example shown in Figure 20. Clamping system that only requires a hard surface and a hammer. The upper part of the fastener has special hooks which, during assembly, stop on the lower part of the coupler, catching on convex bridges.

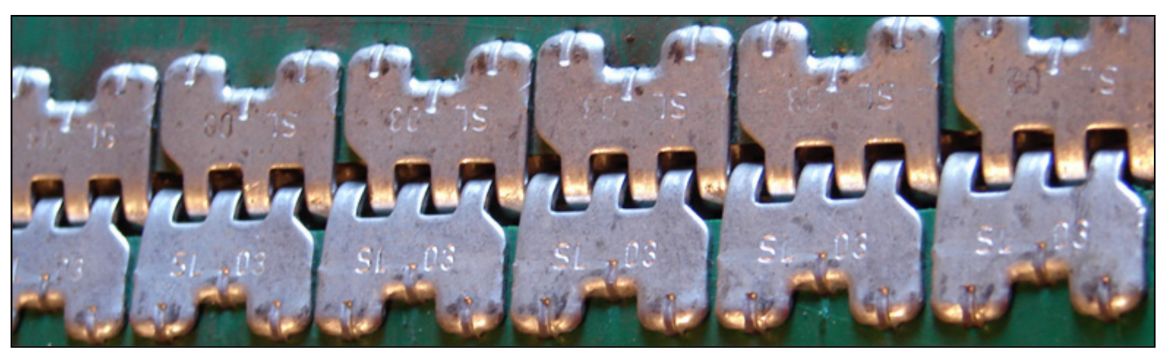

Figure 20. Metal clamps fastening: general view [26].

\subsection{Detachable Sewn Fastener}

An example is shown in Figure 21. For polyester belts. Application: with metal detectors, food or pharmaceutical processing (e.g., dough transport), X-ray equipment, baggage inspection, with delicate products. For belt applications with small pulleys that require non-metal and low-profile fasteners. Detachable connection thanks to a removable pin. Available with white or blue polyester (materials compliant with FDA-US Food Contact Materials Regulation), black polyester and PEEK (Polieteroeteroketon) for high temperature applications. It is recommended that the installation of the couplings be performed by a qualified workshop experienced in splicing the belt into a spiral lace.
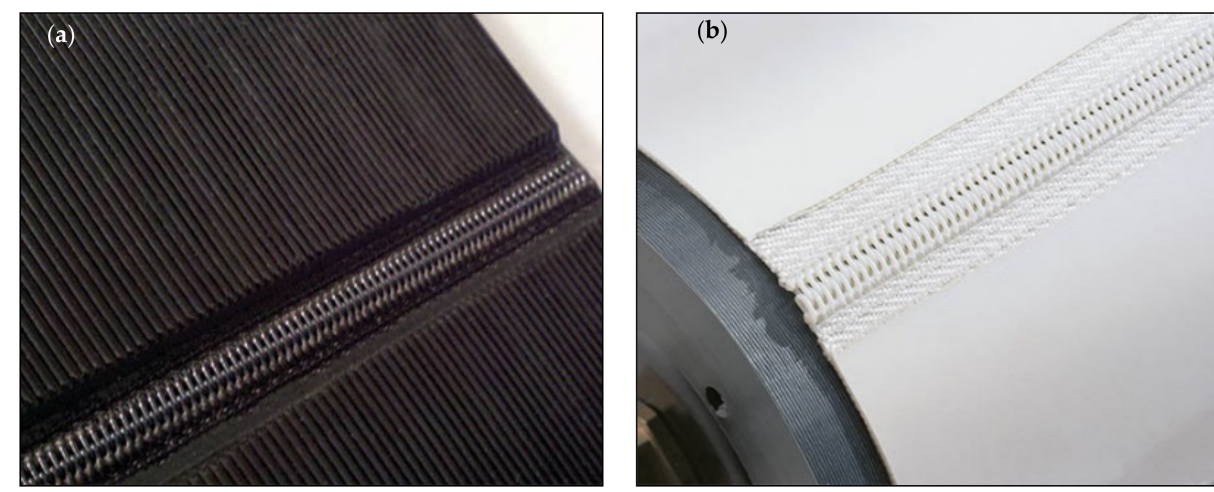

Figure 21. Sewn fastening: (a) black lacing; (b) white lacing [25]. 


\subsection{Solid Fastener with Rivets Attachment Method}

An example that uses plates is shown in Figure 22. Application: sand, gravel, cement, in mining, crushed stone, coal, salt, grain transport (if plates are made of Everdur). Table 10, below, shows what the fasteners are resistant to, depending on the material with which it is made.
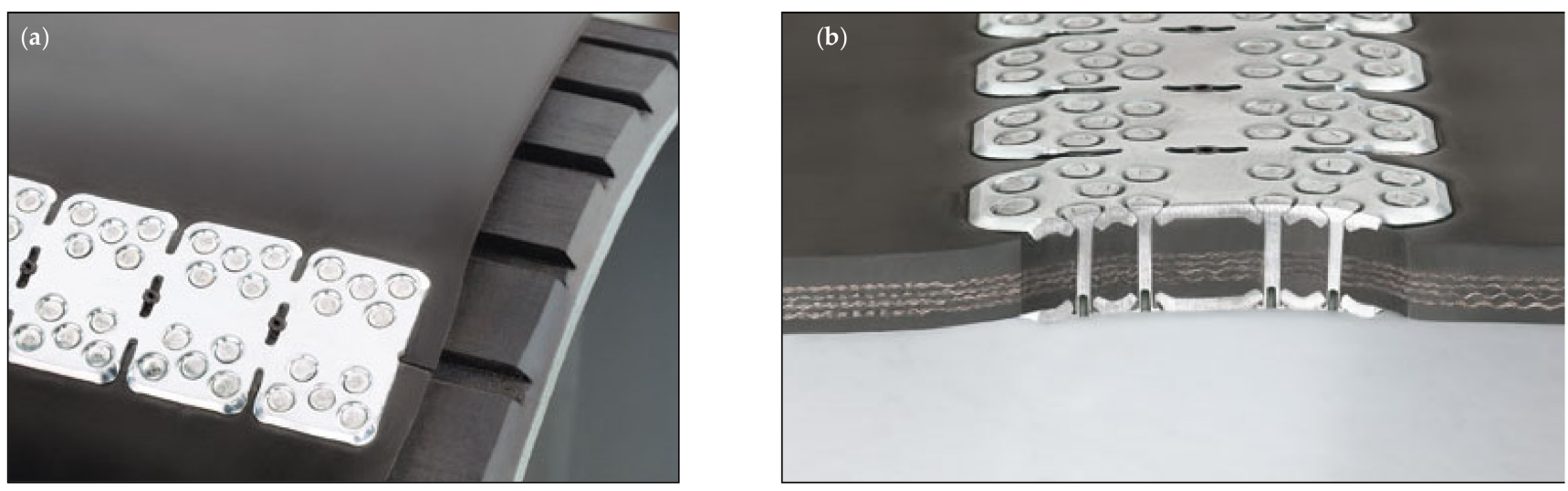

Figure 22. Rivet solid plate fastening: (a) general view using five contact points at each end of the belt; (b) cross section view using seven contact points at each end of belt [25].

Table 10. Fastener Material Characteristics ranging from one plus sign $(+)$ to four plus signs $(++++)[25]$.

\begin{tabular}{ccccc}
\hline Material of Fastener & Magnetic & $\begin{array}{c}\text { Abrasion } \\
\text { Resistant }\end{array}$ & $\begin{array}{c}\text { Chemical } \\
\text { Resistant }\end{array}$ & Rust Resistant \\
\hline Galvanized Steel & Yes & +++ & + & ++ \\
400 Stainless Steel & Yes & +++ & ++ & +++ \\
300 Stainless Steel & Slightly & +++ & +++ & ++++ \\
MegAlloy ${ }^{\circledR}$ & Yes & ++++ & + & + \\
Everdur & No & + & + & + \\
\hline
\end{tabular}

The plates can be non-sparking and non-magnetic when made from a material called Everdur. Installation is carried out using a special portable tool. Can be installed manually, but also using a pneumatic driver.

\subsection{Solid Fastener with Bolts/Screws Attachment Method}

An example is shown in Figure 23. Available in five material variants-Table 11.
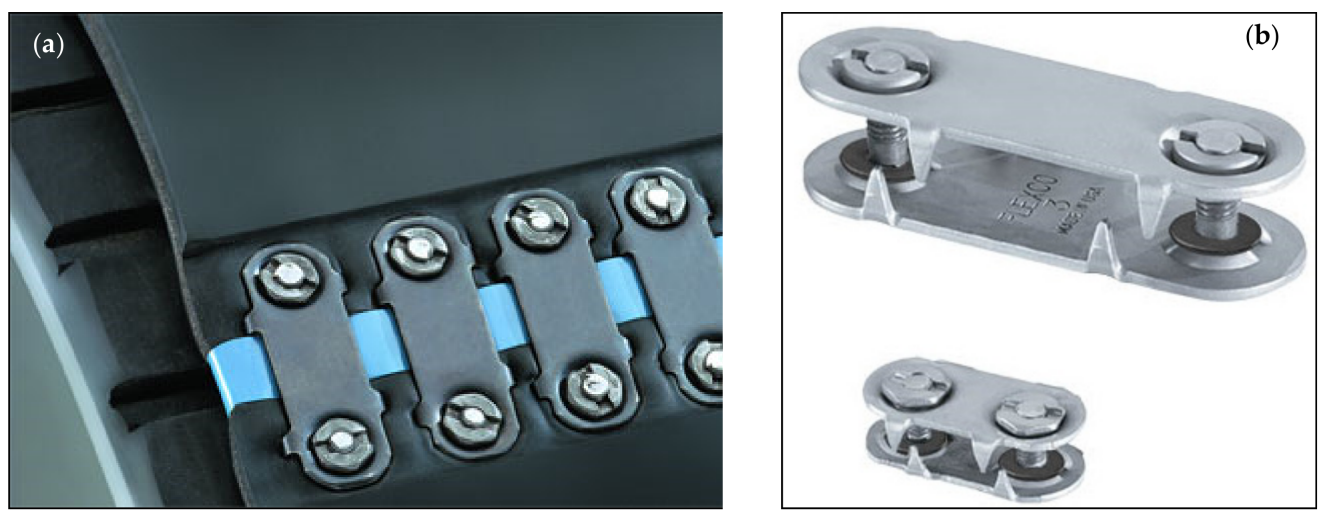

Figure 23. Bolt solid plate fastening: (a) general view, (b) single fastener [25]. 
Table 11. Fastener Material Characteristics ranging from one plus sign $(+)$ to four plus signs $(++++)[25]$.

\begin{tabular}{|c|c|c|c|c|c|}
\hline $\begin{array}{l}\text { Material of } \\
\text { Fastener }\end{array}$ & Magnetic & $\begin{array}{l}\text { Abrasion } \\
\text { Resistant }\end{array}$ & $\begin{array}{l}\text { Chemical } \\
\text { Resistant }\end{array}$ & $\begin{array}{c}\text { Rust } \\
\text { Resistant }\end{array}$ & Picture \\
\hline Steel & Yes & +++ & + & + & \\
\hline $\begin{array}{c}300 \text { Stainless } \\
\text { Steel }\end{array}$ & Slightly & +++ & +++ & ++++ & \\
\hline MegAlloy ${ }^{\circledR}$ & Yes & ++++ & + & + & \\
\hline Evedur & No & + & + & + & \\
\hline $\begin{array}{c}\text { Rubber-Covered } \\
\text { Steel }\end{array}$ & Yes & ++++ & + & + & \\
\hline
\end{tabular}

The bolt solid plate connection is the solution to the toughest requirements of conveyor belts. Designed in the form of plates compressed on both sides by screws. The plates have special hooks (shown in Figure 23b) that are shaped so that they penetrate the belt without damaging the cover.

It is possible that the upper part is covered with rubber. This system can also be used in the arrangement of the so-called WEDLOK ${ }^{\circledR}$ for high tension splice. It uses standard connection plates, but additional special plates are supplied that allow a characteristic seam at a specific angle. Individual fasteners of this system can also serve as repair kits for broken conveyor belts.

The next example uses a rubber joint instead of metal plates—shown in Figure 24. Application: quarries, cement plants, and mines, if the fastener is made out of steel and gold mines, phosphate mines, sorting center, fertilizer plant, recycling facilities and salt handling if the fastener is made out of stainless steel. This fastener is available in several qualities of rubber, shown below in Table 12. Depending on this material, the fastener shows different resistance properties.
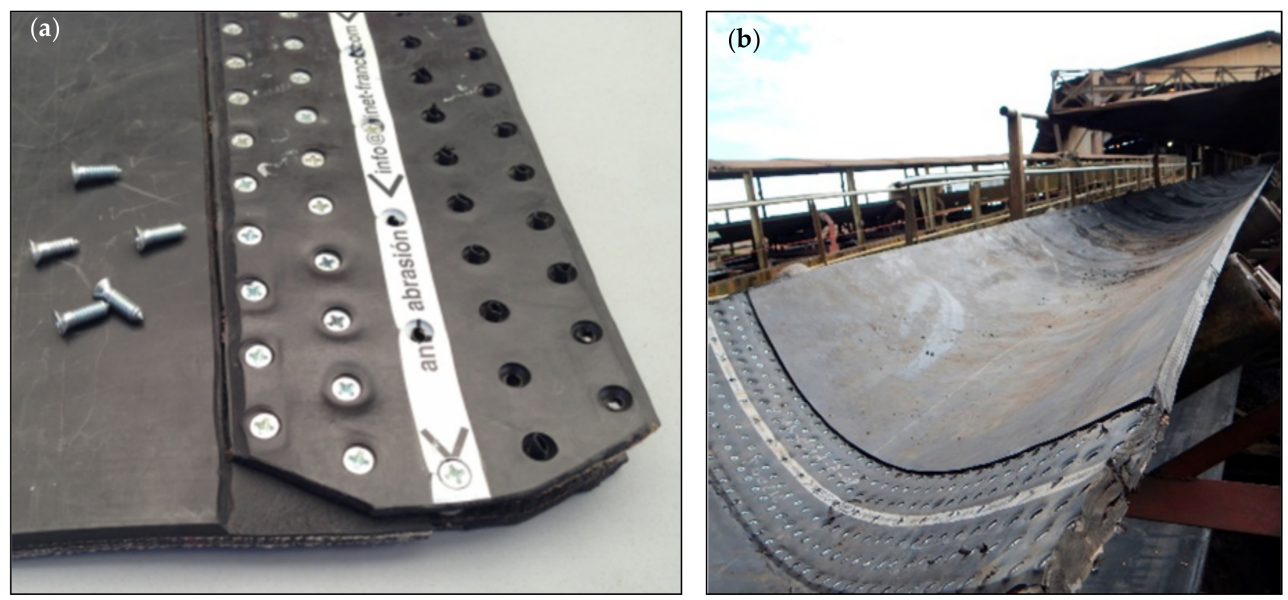

Figure 24. Screws rubber splice fastening: (a) one end of the belt attached, (b) suitable for trough systems of rollers of a belt conveyor [26]. 
Table 12. Several qualities of rubber splice [26].

\begin{tabular}{|c|c|}
\hline Variant Name & Parameter Description \\
\hline Abrasion Resistant & with a high resistance of rubber abrasion to $50 \mathrm{~mm}^{3}$ \\
\hline Heat Resistant & $\begin{array}{l}\text { in systems with temperatures up to } 150^{\circ} \mathrm{C}\left(302^{\circ} \mathrm{F}\right) \text { continuous and } \\
\qquad 170^{\circ} \mathrm{C}\left(338^{\circ} \mathrm{F}\right) \text { flash }\end{array}$ \\
\hline $\begin{array}{l}\text { Heat Retardant } \\
\text { Oil Retardant }\end{array}$ & $\begin{array}{c}\text { will withstand from } 170{ }^{\circ} \mathrm{C} \text { continuous }\left(338^{\circ} \mathrm{F}\right) \text { to } 200{ }^{\circ} \mathrm{C}\left(392^{\circ} \mathrm{F}\right) \text { flash } \\
\text { for surfaces which require oil and solvent resistance }\end{array}$ \\
\hline Fire Resistant & $\begin{array}{l}\text { fabricated in accordance with ISO } 340 \text { and ISO 284, ensures security of } \\
\text { silos and underground mines in fire-resistant and } \\
\text { antistatic environments }\end{array}$ \\
\hline Very low temperature & $\begin{array}{l}\text { resists even at low temperatures until }-30^{\circ} \mathrm{C}\left(-22^{\circ} \mathrm{F}\right)-50^{\circ} \mathrm{C} \\
\left(-58^{\circ} \mathrm{F}\right) \text { on demand }\end{array}$ \\
\hline
\end{tabular}

Structurally, it is a flexible rubber connector in which threaded screws are applied. Two rubber sheets are pre-connected with screws and spaced apart with plastic sleeves. A skived end of the belt is placed in the gap between the rubber panels. Special cutting and skiving tools are available for the installation.

An even better variation of the previous solution is the example in Figure 25. This is sort of a step forward from the standard solution. The difference is the use of inserts that act as washers for screws, whose number has been reduced, making installation easier and faster. The fastener integrates better with the belt, the strength has been improved, the abrasion resistance has been increased, and the lacing has been made more flexible. The is the possibility to use smaller pulley diameters.
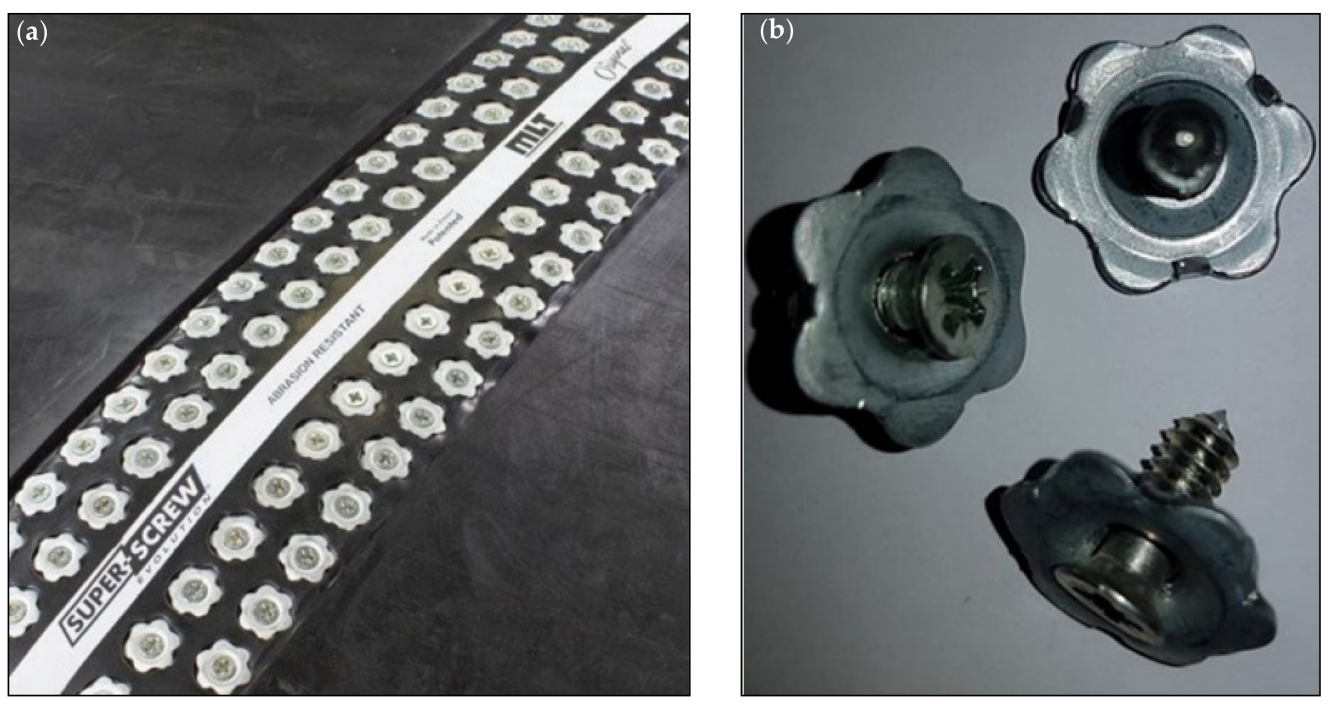

Figure 25. Screws rubber splice fastening: (a) general view; (b) view of the screw embedded in a insert with hooks [26].

\section{Summary}

The most important aspect in choosing the right fastener is the type of application -where and for which industry the conveyor will be used. The application can be for light, medium and heavy industry. This is related to the magnitude of the tensile stresses of the conveyor belt under the working load, and this in turn with the possibility of transferring given stresses through individual types of connections. An important aspect resulting from the above is also the type of transported goods and its relationship with the material of the conveyor belt and the material of the mechanical joint itself. If you are transporting food, your focus should be on FDA-approved conveyor belt materials such as TPU, PVC, PU, PES. These types of belts are more suitable for hook connections or one that is compatible with the conveyor belt material-a patch of identical material. If you are transporting metal 
parts that cannot react with other metal surfaces, choose a non-metallic connection material, e.g., plastic, Evedur, or non-magnetic stainless steel. If the transport area must be protected against fire, a non-sparking connection must be selected. An important geometric aspect on which the selection of the connection depends is the diameter of the pulley. For each fastener, the minimum pulley diameter at which the fastener can be used is given. However, the most important thing is that detachable connections can be applied to relatively smaller diameters than permanent connections.

The next aspect is how to install. This includes considerations such as whether it is an easy or difficult method, whether it requires special or simple equipment, whether it can be assembled manually or with the use of pneumatic/hydraulic/electric support, whether the connection must be made by yourself, whether it is possible at the manufacturer's site, whether you need a small number of tools or a large number, whether commonly used or specialized tools.

You also need to consider what degree of cleanliness you want to maintain when using the conveyor. Some connections are unfortunate in this respect, as they have numerous cavities and openings in which dirt can enter. Belts with a detachable connection are better for cleaning. The belt can then be removed from the conveyor and cleaned outside the conveyor system.

If significant abrasive forces occur during use, then either choose a material for the fastener (e.g., MegAlloy) that is extremely abrasion resistant or use a rubber protection for the fasteners.

It is also worth paying attention to the thickness of the connection-whether it creates a low-profile system or not. This is very important, especially in the context of the relationship with additional devices mounted on the conveyor and having direct contact with the conveyor belt, such as a scraper.

Figure 26 shows the first design map, thanks to which it is possible to select a mechanical connection for a conveyor belt with a thickness of 0 to $18 \mathrm{~mm}$ and a fastener strength of 0 to $60 \mathrm{kN} / \mathrm{m}$. The areas of application of individual connections are presented in the form of triangles, in which the hypotenuse is a curve approximating (as a linear function) the actual gradation of the relationship between the thickness of the belt and the strength of the connector in a given size. Some connections, on the other hand, are presented in the form of straight lines (as a constant function) - such as 3 and 7. This means that all connection sizes from a given group have the same strength, but are designed for different thicknesses of the belt.

Figure 27 shows the second design map, thanks to which it is possible to select a mechanical connection for a conveyor belt with a thickness of 0 to even $54 \mathrm{~mm}$ and a fastener strength of 0 to even $360 \mathrm{kN} / \mathrm{m}$. These are for more demanding applications.

Figure 28 shows the third design map, thanks to which it is possible to select a mechanical connection for a conveyor belt with a MIN. Pulley diameter of 0 to $360 \mathrm{~mm}$ and a fastener strength of 0 to $60 \mathrm{kN} / \mathrm{m}$. Some connections are not shown as triangular areas like 3 and 7 . They are only indicated by the reference line. This means that they are only available in a size that has a certain constant strength and one value for the minimum drive roller diameter.

Figure 29 shows the fourth design map, thanks to which it is possible to select a mechanical connection for a conveyor belt with a MIN. Pulley diameter of 0 to $1350 \mathrm{~mm}$ and a fastener strength of 0 to $360 \mathrm{kN} / \mathrm{m}$. 


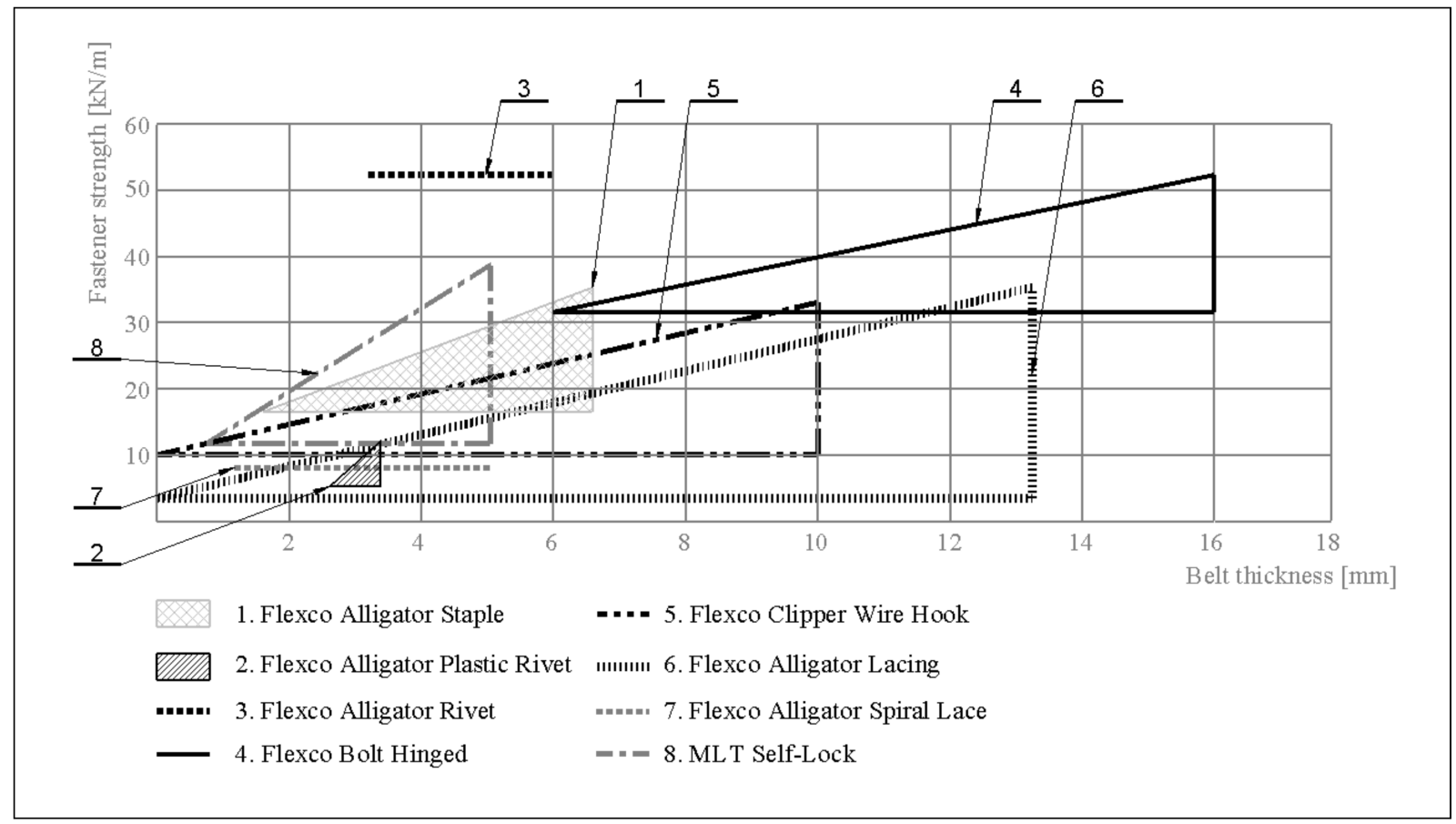

Figure 26. Design map for the selection of a mechanical connection in the range of conveyor belt thickness from 0 to approximately $18 \mathrm{~mm}$ and in the range of fastener strength from 0 to approximately $60 \mathrm{kN} / \mathrm{m}$.

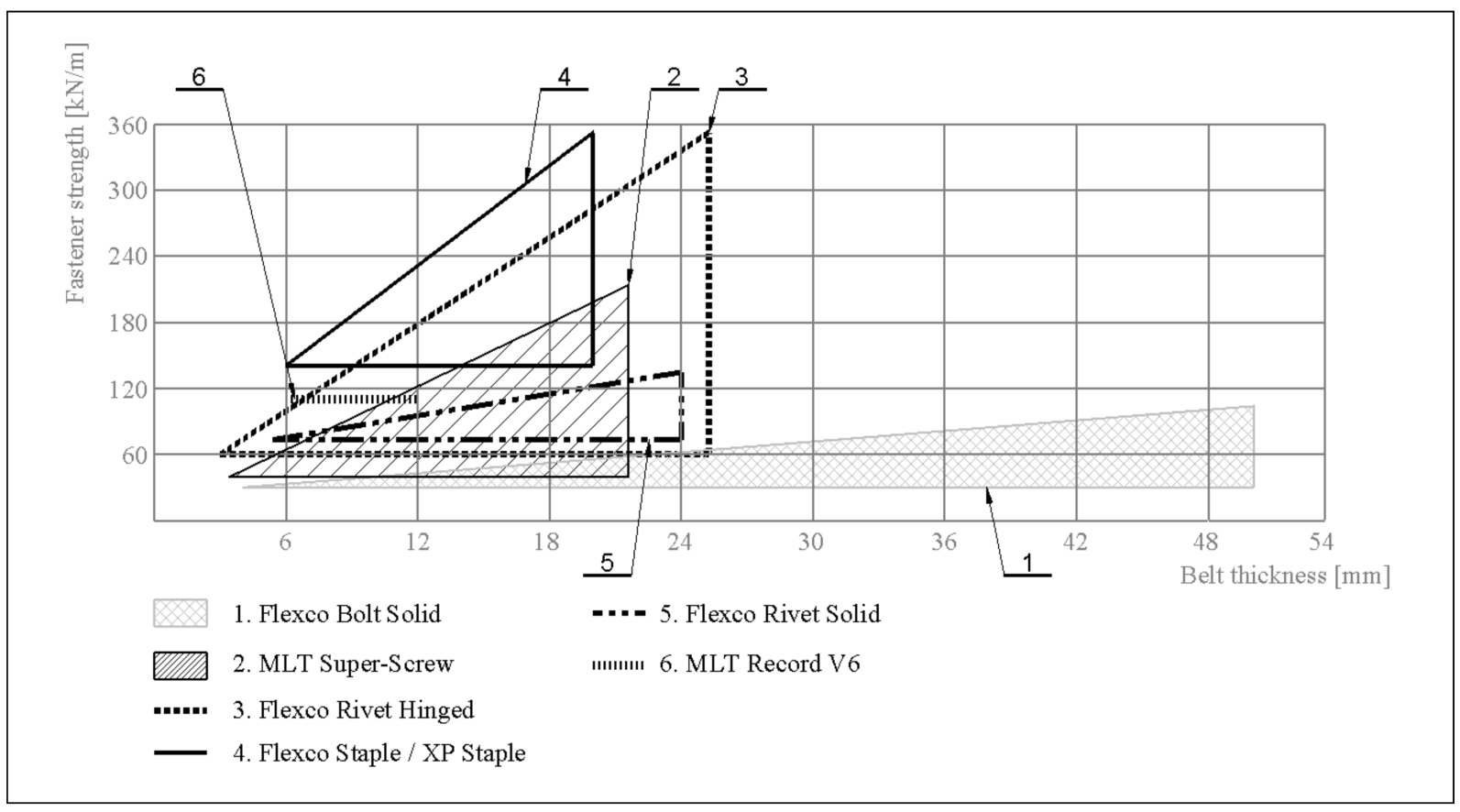

Figure 27. Design map for the selection of a mechanical connection in the range of conveyor belt thickness from 0 to approximately $54 \mathrm{~mm}$ and in the range of fastener strength from 0 to approximately $360 \mathrm{kN} / \mathrm{m}$. 


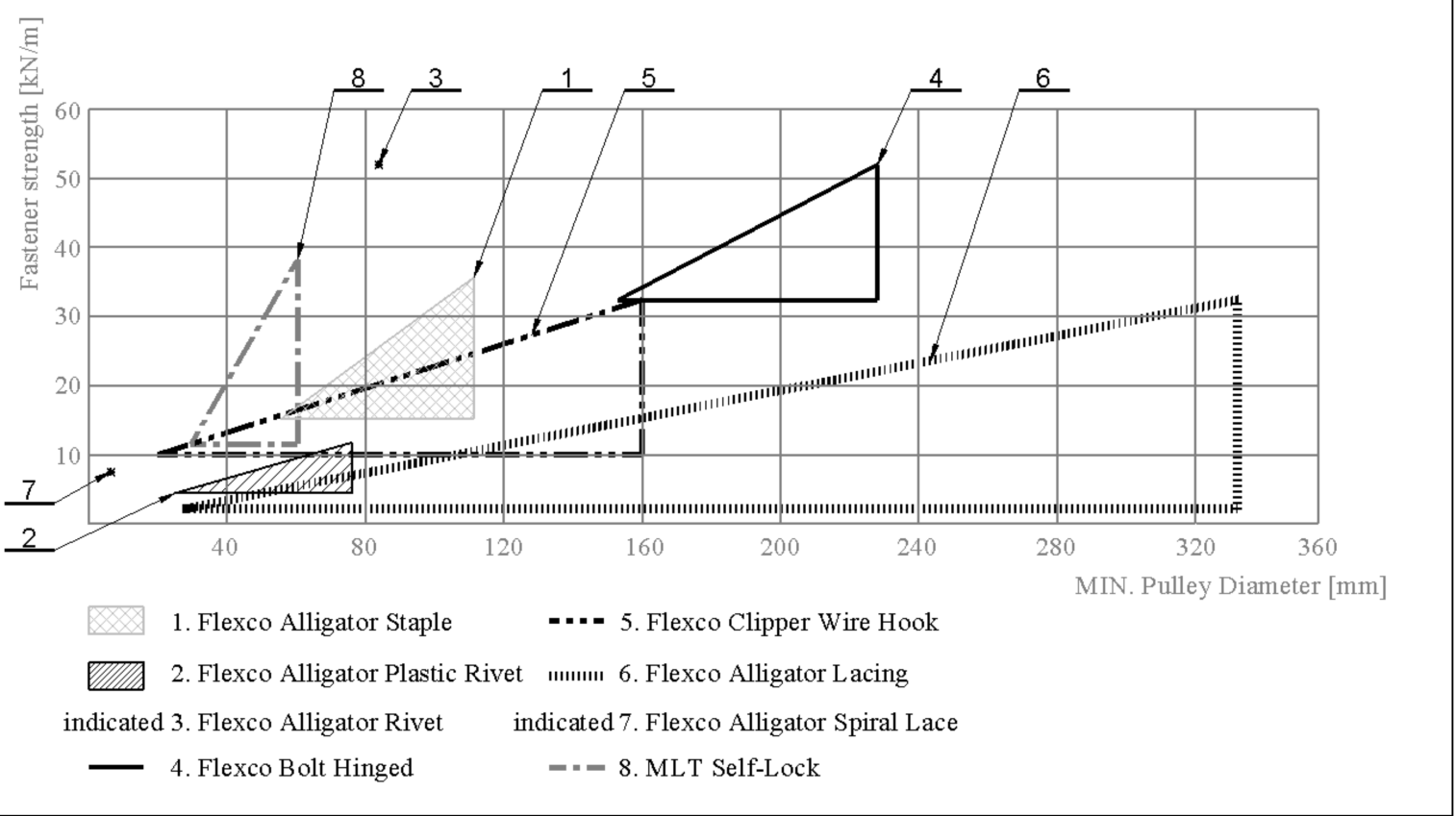

Figure 28. Design map for the selection of a mechanical connection in the range of MIN. Pulley diameter from 0 to approximately $360 \mathrm{~mm}$ and in the range of fastener strength from 0 to approximately $60 \mathrm{kN} / \mathrm{m}$.

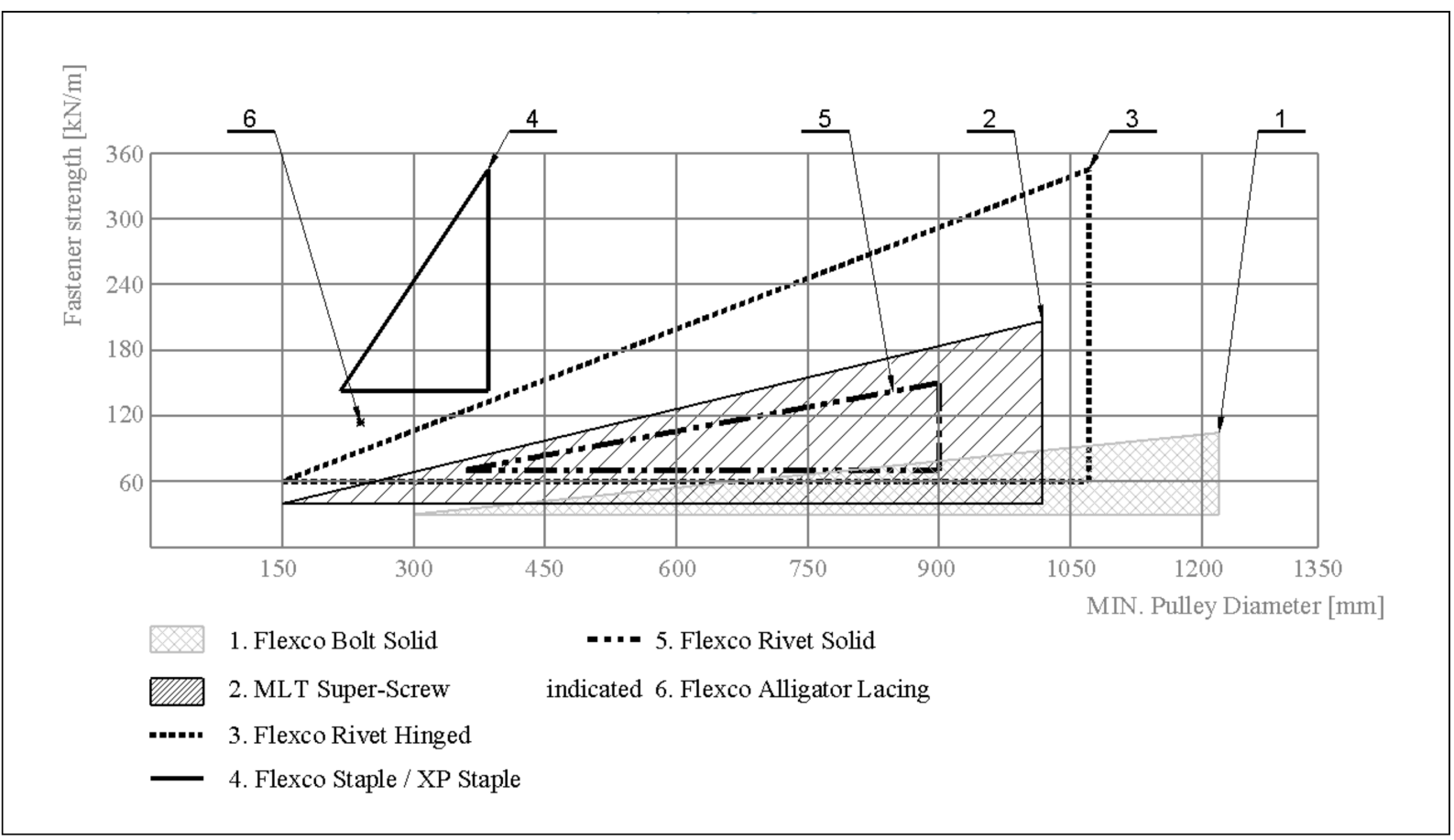

Figure 29. Design map for the selection of a mechanical connection in the range of MIN. Pulley diameter from 0 to approximately $1350 \mathrm{~mm}$ and in the range of fastener strength from 0 to approximately $360 \mathrm{kN} / \mathrm{m}$.

By reviewing the mechanical fasteners, it was possible to notice an extensive variety of design solutions. In summary, the following types of construction nodes are worth paying attention to when determining the optimal geometric and material properties of connections for further research, mainly in the context of interference with the internal structure of the belt: 
- Material: metal (mainly steel, but also light metals, such as titanium), non-metal (plastic, rubber).

- Separable and non-separable.

- Complexity: monolithic (uniform), several partial, with intermediate elements.

- The method of integration with the belt (clamp form): teeth, legs, claws, spikes, hooks, screws, bolts, rivets, weld, pins, staples, nails, spiral lacing

- Clamp pattern (selected): staples in a horizontal pattern, staples in a diagonal pattern, staples in a V-pattern, meander pattern, multi-row pattern, etc.

- Belt preparation: with a one-sided initial skiving (material loss in the thickness of the belt), with a double-sided initial skiving, cutting the belt widthwise, cutting the belt diagonally (at a specific angle), form cut, pre-drilling, preliminary puncturing, etc.

- Number of fasteners: number of bolts, number of rivets, number of staples, etc.

- Effect of joint height on roll integrity and with e.g., scraper: low profile joints, normal joints, high profile joints, joints compatible with the belt thickness.

- Complexity of connection techniques: only mechanical, hybrid (mechanical connection with any other, e.g., glued).

- Surface contact with the belt (contact area of the contact surfaces of the joints with the top and bottom layers of the belt).

- Type of belt penetration: material damage (puncture e.g., when riveting or screwing in screws), elastic/plastic deformation (e.g., by clamping the belt from shaped hooks).

Author Contributions: Conceptualization, K.K., D.W. and K.T.; methodology, K.K., D.W. and K.T.; software, K.K.; validation, K.K., D.W. and G.D.; formal analysis, K.K.; investigation K.K. and D.W.; resources, K.K., G.D.; data curation, K.K.; writing—original draft preparation K.K.; writing—review and editing, K.K., D.W., K.T., A.K. and G.D.; visualization, K.K.; supervision, K.T. and A.K.; project administration, K.K. All authors have read and agreed to the published version of the manuscript.

Funding: This research received no external funding.

Institutional Review Board Statement: Not applicable.

Informed Consent Statement: Not applicable.

Data Availability Statement: Data sharing not applicable.

Conflicts of Interest: The authors declare no conflict of interest.

\section{References}

1. Goździecki, M.; Świątkiewicz, H. Przenośniki; Wydawnictwa Naukowo-Techniczne: Warszawa, Poland, 1979; ISBN 83-204-0081-3.

2. Domek, G.; Wilczyński, M.; Woźniak, T. Application of flat belts in advanced machine constructions. Mechanik 2017, 90, 1048-1050. [CrossRef]

3. Guzha, E.D.; Romanenko, V.A.; Skorokhod, M.A. Simulation and histogram modeling of conveyor systems. In IOP Conference Series: Materials Science and Engineering, Mechanical and Automation Engineering for Industry 2020; MIP: Engineering-2020; IOP Publishing: Bristol, UK, 2020; Volume 862, p. 032008. [CrossRef]

4. Kawalec, W.; Suchorab, N.; Konieczna-Fuławska, M.; Król, R. Specific Energy Consumption of a Belt Conveyor System in a Continuous Surface Mine. Energies 2020, 13, 5214. [CrossRef]

5. Kozhushko, G.G.; Yampolsky, D.A.; Lukashuk, M.D. Analysis of forced vibrations of conveyor belts. In IOP Conference Series: Materials Science and Engineering, International Conference on Modern Trends in Manufacturing Technologies and Equipment 2020; ICMTMTE; IOP Publishing: Bristol, UK, 2020; Volume 709, p. 033022. [CrossRef]

6. Rudawska, A.; Madlenák, R.; Madlenáková, L.; Droździel, P. Investigation of the Effect of Operational Factors on Conveyor Belt Mechanical Properties. Appl. Sci. 2020, 10, 4201. [CrossRef]

7. Pihnastyi, O.; Khodusov, V. Neural model of conveyor type transport system. In CEUR Workshop Proceedings; 2020. Available online: https://www.researchgate.net/publication/342667146_Neural_model_of_conveyor_type_transport_system (accessed on 12 December 2020).

8. Boslovyak, P.V.; Lagerev, A. Optimization of the conveyor transport cost. IFAC-PapersOnLine 2019, 52, 397-402. [CrossRef]

9. Wheatley, G. Design of a Conveyor Belt Turning Frame. In Industrial Engineering \& Management; 2018; Volume 7, ISSN 2169-0316. Available online: https:/ / www.researchgate.net/publication/339615559_design-of-a-conveyor-belt-turning-frame (accessed on 12 December 2020). [CrossRef] 
10. Wojtkowiak, D.; Talaśka, K.; Malujda, I.; Domek, G. Estimation of the perforation force for polymer composite conveyor belts taking into consideration the shape of the piercing punch. Int. J. Adv. Manuf. Technol. 2018, 98, 2539-2561. [CrossRef]

11. Wojtkowiak, D.; Talaśka, K. Determination of the effective geometrical features of the piercing punch for polymer composite belts. Int. J. Adv. Manuf. Technol. 2019, 104, 315-332. [CrossRef]

12. Wojtkowiak, D.; Talaśka, K.; Wilczyński, D. Evaluation of the belt punching process efficiency based on the resistance force of the compressed material. Int. J. Adv. Manuf. Technol. 2020, 110, 717-727. [CrossRef]

13. Ahad, N.A. A Recent blend of thermoplastic polyurethane (TPU), Conference Paper in IOP Conference Series Materials Science and Engineering. In Proceedings of the IOP Conference Series: Materials Science and Engineering, International Conference on Sustainable Materials (ICoSM 2020), Pahang, Malaysia, 30 March 2020. [CrossRef]

14. Xu, T.; Shen, W.; Lin, X.; Xie, Y.M. Mechanical Properties of Additively Manufactured Thermoplastic Polyurethane (TPU) Material Affected by Various Processing Parameters. Polymers 2020, 12, 3010. [CrossRef] [PubMed]

15. Wojtkowiak, D.; Talaśka, K.; Malujda, I.; Domek, G. Vacuum conveyor belts perforation—methods, materials and problems. Mechanik 2017, 90, 1138-1142. [CrossRef]

16. Romanchev, I.O. The mathematical model of the belt conveyor. In Proceedings of the IOP Conference Series: Materials Science and Engineering, International Conference on Mechanical Engineering, Automation and Control Systems 2018, Novosibirsk, Russia, 12-14 December 2018; Volume 560, p. 012035, MEACS2018. [CrossRef]

17. Li, J.; Pang, X. Belt Conveyor Dynamic Characteristics and Influential Factors, Hindawi. Shock. Vib. 2018, 2018, 8106879. [CrossRef]

18. Ibishi, I.; Latifi, A.; Ibishi, G.; Sejdiu, K.; Shala-Galica, M.; Latifi, B. Calculation of tension force of belt conveyor. Int. J. Eng. Sci. Technol. 2012, 4, 4886-4892.

19. Trufanova, I.S.; Avksentiev, S.Y. Mathematical model of belt conveyor intermediate drive with baffles. In Proceedings of the IOP Conference Series: Earth and Environmental Science, International Conference on Innovations and Prospects of Development of Mining Machinery and Electrical Engineering 2019, Saint-Petersburg Mining University, Saint-Petersburg, Russia, 24-27 April 2019; Volume 378, p. 012033, IPDME 2019. [CrossRef]

20. Hussein, E.K. Belts Systems, Types of Belts Systems (Flat Belt Drives), ATU, TCM. In Theory of Machines-Belts Drives; 2016. Available online: https://www.researchgate.net/publication/307431645_BELTS_SYSTEMS_TYPES_OF_BELTS_SYSTEMS_FLAT_ BELT_DRIVES (accessed on 12 December 2020).

21. Finnegan, K. Selecting Plate-Type Belt Fastener systems for Heavy-Duty conveyor-Belt Operations, Bulk Solids Handling. Sel. Belt Fasten. Syst. 2001, 21, 315-319.

22. Markowski, M. Przenośniki cz. 1; Wydawnictwo Politechniki Łódzkiej: Łódź, Poland, 1995; ISBN 8386453443.

23. Group Work. Katalog Przenośników Taśmowych KPT-3; Wydawnictwo Centralnego Biura Konstrukcji Maszynowych: Bytom, Poland, 1962.

24. Website of the HABASIT AG, Manufacturer of Conveyor Belts. Available online: www.habasit.com (accessed on 12 December 2020).

25. Website of the FLEXCO, Manufacturer of Fastening System for Conveyor Belts. Available online: www.flexco.com (accessed on 12 December 2020).

26. Website of the MLT, Manufacturer of Fastening System for Conveyor Belts. Available online: www.mlt-lacing.com (accessed on 12 December 2020). 